Arkivoc

Free to Authors and Readers
A Platinum Open Access Journal for Organic Chemistry

Review

DOAJ Seal

\title{
Poly(ADP-ribose): the structure and the synthesis
}

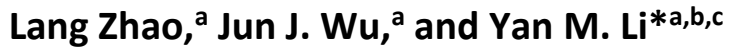 \\ ${ }^{a}$ Key Lab of Bioorganic Phosphorus Chemistry\& Chemical Biology, Department of Chemistry, Tsinghua \\ University, Beijing 100084, China \\ ${ }^{b}$ Beijing Institute for Brain Disorders, Beijing 100069, China \\ ${ }^{c}$ Center for Synthetic and Systems Biology, Tsinghua University, Beijing 100084, China \\ Email: liym@mail.tsinghua.edu.cn
}

This paper is dedicated to Professor Horst Kunz for his 80th anniversary

Received 07-24-2020

Accepted 09-02-2020

Published on line $09-10-2020$

\section{Abstract}

Poly(ADP-ribose) belongs to a momentous post-translational modification of eukaryotic nuclear protein. Protein poly(ADP-ribosyl)ation mediates numerous cell signalings and is related to some diseases. Poly(ADPribose) is currently available through enzymatic or chemical synthesis. Herein, we summarize the structure characteristics and recent developments in the synthesis of poly(ADP-ribose) from a chemical point of view.

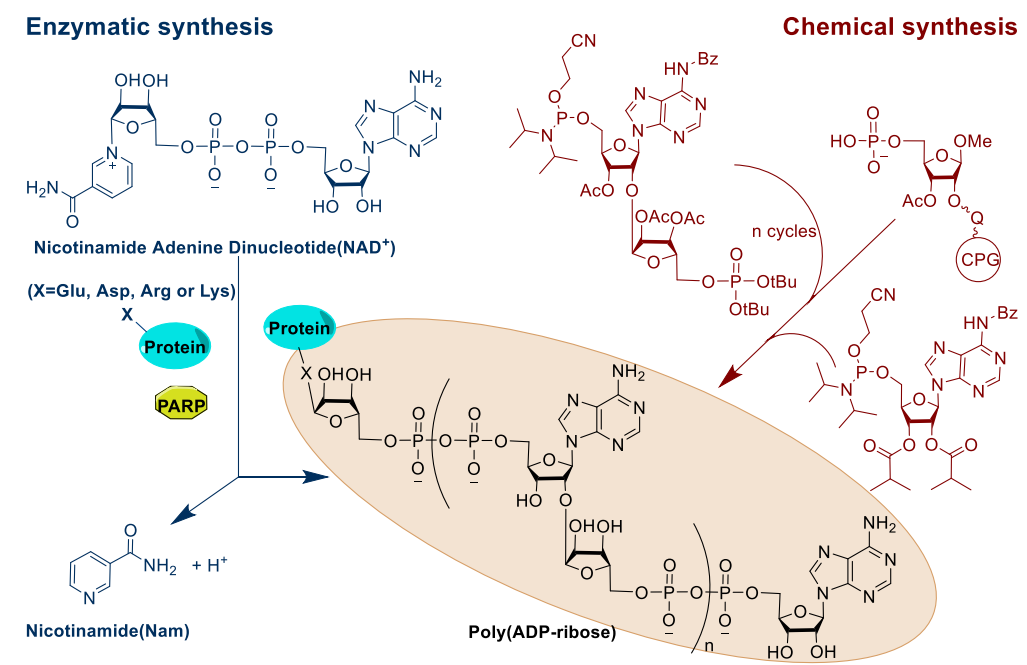

Keywords: Poly(ADP-ribose), post-translational modification, poly(ADP-ribosyl)ation, structure, synthesis 


\section{Table of Contents}

\section{Introduction}

2. The Structure of Poly(ADP-Ribose)

2.1. Molecular skeleton of poly(ADP-ribose)

2.2. Enzymatic hydrolysis of poly(ADP-ribose)

2.3. Poly(ADP-ribose) recognition of protein

3. Synthesis of Poly(ADP-Ribose)

3.1. Enzymatic synthesis of poly(ADP-ribose)

3.2. Chemical synthesis of poly(ADP-ribose)

3.2.1. Synthesis of disaccharide nucleoside

3.2.2. Synthesis of the pyrophosphate linkage

3.2.3. Synthesis of poly(ADP-ribose)

4. Conclusions

\section{Introduction}

Post-translational modification is very important for the functions of proteins. However, abnormal modifications of proteins will lead to serious cell dysfunction. Alzheimer's disease (AD) and Parkinson's disease (PD) are considered as two common neurodegenerative diseases, which are generally caused by protein aggregates. ${ }^{1}$ Some investigations have found that post-translational modifications are able to regulate protein aggregation processes, such as O-GIcNAcylation of AD-associated tau protein at Ser $356^{2}$ and phosphorylation of PD-associated alpha-synuclein ( $\alpha$-Syn) at Ser129. ${ }^{3}$ Aberrant truncated glycosylation of tumor-associated mucin-1 (MUC1) caused by glycosyltransferases with abnormal activity induces MUC1-specific immune responses, showing the potential application in antitumor MUC1 vaccines. ${ }^{4,5}$ Poly(adenosine diphosphate ribose) (abbreviated as Poly(ADP-ribose) or PAR), which can covalently bind to amino acid residues (such as Glu, Asp, Arg and Lys), is also a distinctive post-translational modification of eukaryotic nuclear protein..$^{6-9}$ PAR regulates extensive cellular processes, such as ATP-dependent energy metabolism, ${ }^{10}$, 11 chromatin remodelling, ${ }^{12-16}$ DNA-damage repair, ${ }^{15}$ cell death, ${ }^{17}$ gene expression ${ }^{18}$ and cell division. ${ }^{19}$ Protein PARylation, in mechanism, influences protein-protein interactions, which modulates enzyme activity and thus may be related to some diseases. ${ }^{20-23}$

Mono(ADP-ribose)(MAR) or PAR is biosynthesized both in vivo and in vitro under the catalysis of PAR polymerase family (PARPs) which includes 17 enzyme members. Since intracellular protein PARylation initiates, length of PAR increases in the main chain direction by adding ADP one by one from nicotinamide adenine dinucleotide $\left(N A D^{+}\right) \cdot{ }^{6-10}$ In addition, PARylation of DNA at 5' terminal phosphate group improves its stability against phosphatases. Modification with MAR at 3' hydroxyl group and 3' terminal phosphate group of DNA was also reported to produce a ribose-ribose glycosidic bond and a phosphodiester bond, respectively. ${ }^{24}$ As mentioned above, PAR widely participates in biochemical, physiological and pathological processes. Based on these researches, tri(ADP-ribose), a chemically synthesized PAR-mimic molecule, is a more potent effector than di(ADP-ribose) for Amplified in Liver Cancer 1 (ALC1) activation with a nanomolar affinity. Tri(ADP-ribose) was found to abolish the macrodomain-ATPase interaction and to recover the activity of remodeler ALC1, indicating the significance of PAR synthesis in vitro. ${ }^{16}$ 
There is no doubt that synthetic PAR is a useful tool for researchers to understand the precise mechanisms of PAR-mediated protein-protein and protein-nucleic acid interactions. ${ }^{7}$ In 1963 , acid-insoluble poly $(A)$ in chicken hepatocyte nucleus, later confirmed as PAR, was firstly detected. ${ }^{8,25}$ Since then, many biologists have used enzymatic synthesis strategy to produce PAR and subsequently identified the structures and biochemical functions of PAR, as well as the enzymatic activities of PARPs. ${ }^{26-29}$ However, MARylated or PARylated proteins synthesized by enzymatic methods lack molecular homogeneity and require tedious purification. Therefore, chemical synthesis strategies of well-defined PAR or PARylated biopolymer are sharply needed. ${ }^{30}$ Here, we provide a short review about the recent research progress in PAR and we mainly focus on the structure and synthetic strategies (particularly, chemical synthesis) of PAR.

\section{The Structure of Poly(ADP-Ribose)}

\subsection{Molecular skeleton of poly(ADP-ribose)}

PAR, molecularly similar to nucleic acid, is negatively charged and homologous with high molecular weight. ${ }^{6}$ PAR is also considered as the fourth biopolymer, the other three kinds of biopolymer are nucleotides, polypeptides and polysaccharides. These four kinds of biopolymers unexceptionally play key roles in biochemical processes in vivo. ${ }^{31}$ PAR skeleton consists of many 2'-O- $\alpha$-D-ribofuranosyladenosine units linked via pyrophosphate bonds. ${ }^{31}$ ADP-ribose (ADPR) is the monomeric unit of PAR and is a NAD+ derivative. The carbon atom numbering of ADPR is displayed in Figure $1 \mathrm{~A}$. Referred to ADPR for the carbon atom numbering of PAR (Figure 1B), the carbon atoms of ribose in adenosine are numbered $1^{\prime}, 2^{\prime}, 3^{\prime}, 4^{\prime}$ and $5^{\prime}$, respectively, and the carbon atoms of ribose between adenosine and pyrophosphate bond are numbered $1^{\prime \prime}, 2^{\prime \prime}, 3^{\prime \prime}, 4^{\prime \prime}$ and $5^{\prime \prime}$, respectively. ${ }^{6}$ The two adjacent ADPRs in PAR are connected through $\alpha\left(2^{\prime}, 1^{\prime \prime}\right)$-glycosidic bond (the main chain elongated direction), except for the branching point where $\alpha\left(2^{\prime \prime}, 1^{\prime \prime}\right)$-glycosidic bond links the two adjacent ADPRs. ${ }^{32,} 33$ PAR branches at $2^{\prime \prime}-\mathrm{OH}$ every 20 to 50 ADPR units and forms $\alpha\left(2^{\prime \prime}, 1^{\prime \prime}\right)$-glycosidic bond using the same chemistry as the main chain does (Figure 1B). 6, 7, 31-34 The size of PAR synthesized by PARPs can reach up to 400 ADPR units. $^{34}$ The branched structures of PAR were directly observed by dark field electron microscopy ${ }^{35}$ and the branching frequency of PAR was determined by Jacobson et al. ${ }^{27}$. The configuration of PAR was mainly determined by nuclear magnetic resonance spectroscopy. ${ }^{29,} 30,36-38$

A

B
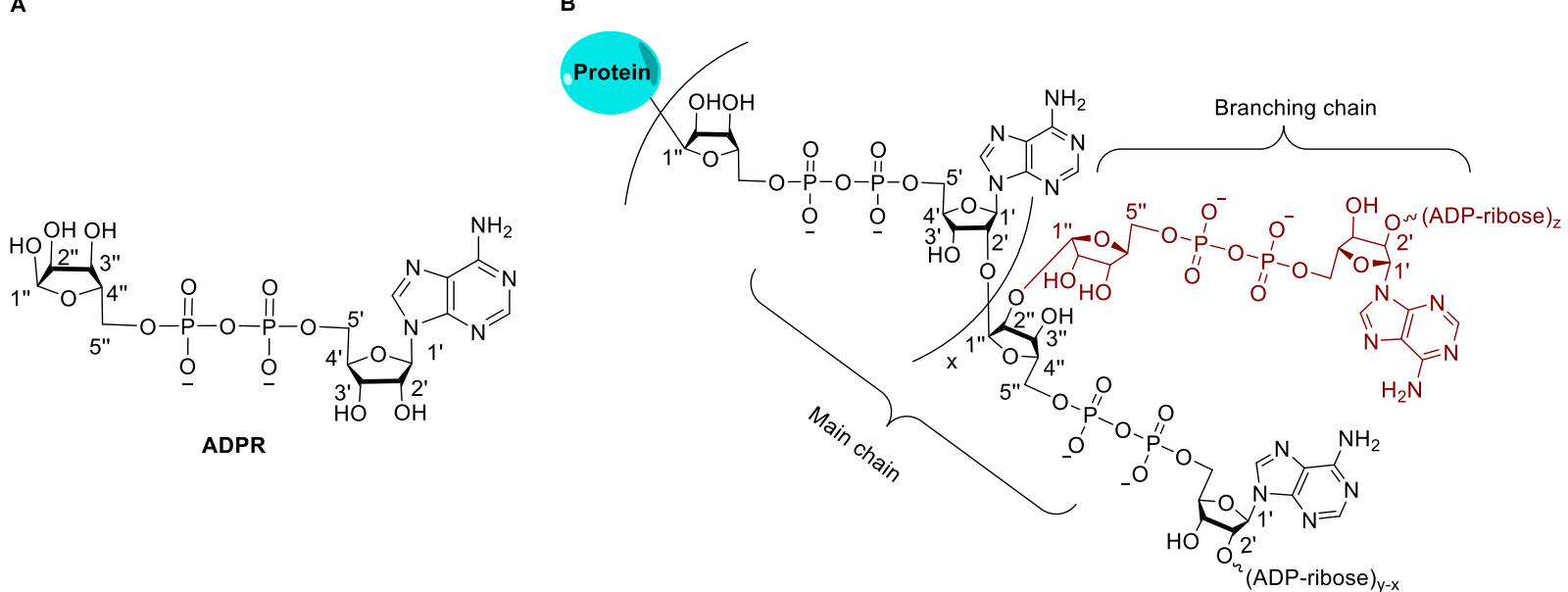

Figure 1. The monomeric unit ADPR (A) and the skeleton structure (B) of native PAR, where $x$ values 20-50 and $(y+z)$ values up to 400 . 
Snake venom phosphodiesterase is a hydrolase that can break pyrophosphate bonds of PAR ${ }^{26,37,39,40}$ producing 5'-AMP, isoADPR and ribose 5'-phosphate attached protein (R-5'-P-Protein, Figure 2 ), which can be used to determine the average chain length of PAR following the formula: ${ }^{26}$

$$
\text { Average chain length }=\frac{5^{\prime}-A M P+i s o A D P R}{5^{\prime}-A M P}
$$

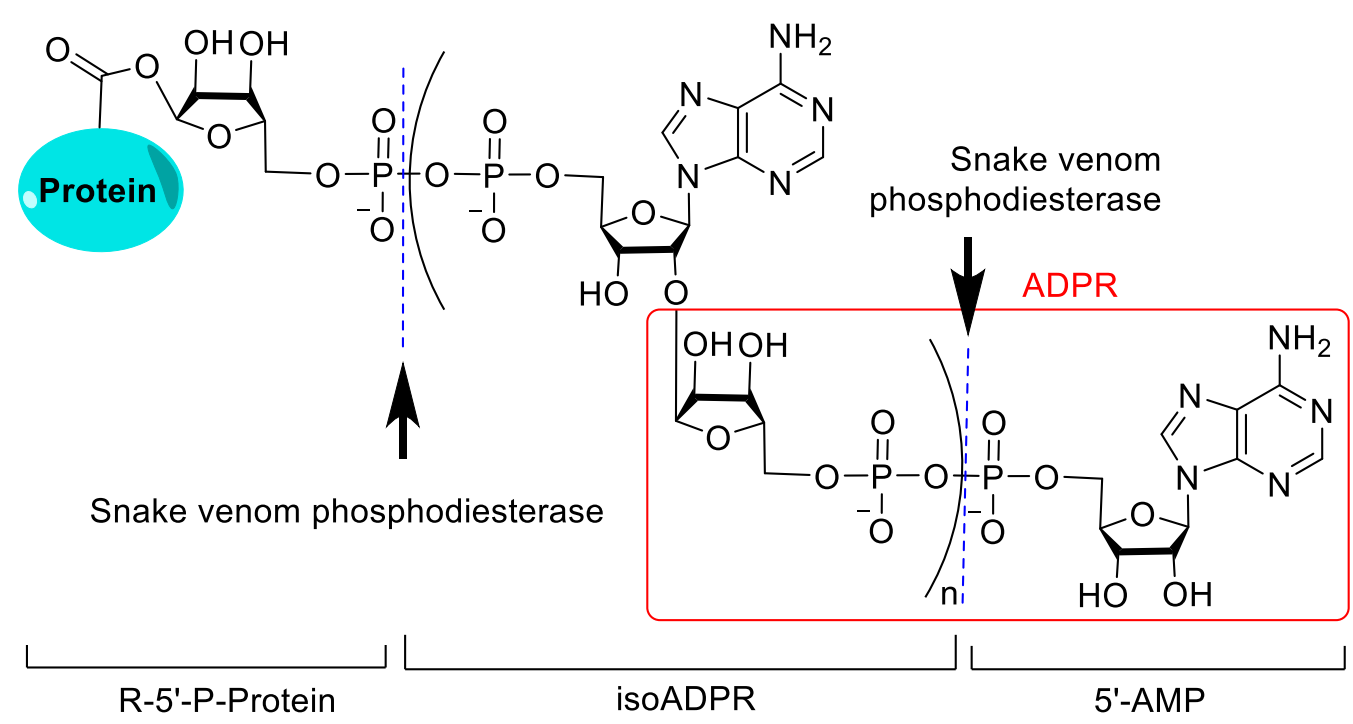

Figure 2. Snake venom phosphodiesterase hydrolyzes pyrophosphate bonds of PAR producing three products.

\subsection{Enzymatic hydrolysis of poly(ADP-ribose)}

PAR was initially found to covalently bind to proteins. However, a few years later, the Rickwood lab revealed that free PAR, not covalently bound to proteins, also existed in cell, ${ }^{26}$ which always derives from the degradation of PAR-protein covalent conjugates by the best known hydrolase, poly(ADP-ribose) glycohydrolase (PARG). PARG, expressed in nearly all eukaryotic cells, is both exo- and endo-glycohydrolase of PAR and can specifically and quickly cleave ribose-ribose $\alpha\left(2^{\prime}, 1^{\prime \prime}\right)$-glycosidic bond between two ADPR units both in main chain and branching chain. ${ }^{41-44}$ PAR cleaved by PARG with exo-glycohydrolase activity produces ADPR monomers. However, intact free PAR can be released from cleaving the glycosidic bond closed to protein by PARG with endo-glycohydrolase activity (Figure 3A). ${ }^{6,7}$ Thus, PAGR functions as opposed to PARPs and is of great importance for DNA damage response. Decomposition of PARylation proteins modified by PARPs generates either ADPR units or dissociative PARs, which in return affect cellular activities. In fact, PARPs and PARG both participate in many intracellular processes, and the cooperation of PARPs and PARG controls the levels and functions of both free PAR and PARylation proteins. ${ }^{6,7,41,42}$ The PAR-protein binding state, as well as its catalytic hydrolysis process by PARG, was revealed by Leys and Ahel who provided the first crystal structure of $T$. curvata PARG-ADPR complex ${ }^{45}$ and $T$. thermophila PARG-ADPR complex. ${ }^{46}$ Leys et al. demonstrated that PAR/PARG ratio was related to the balance between exo- and endo-glycohydrolase activity via crystal structure of $T$. thermophila PARG-PAR9 complex. ${ }^{44}$

In addition, many enzymes have been reported to hydrolyze PARylated proteins, which can be divided into three types (Figure 3B). ${ }^{31,47-50}$ The first type of hydrolase is (ADP-ribofuranosyl)proteinylase, such as ARH1, TARG1 and micro D1/2. ARH1 specifically cleaves MAR from the Lys residue in MARylated protein. TARG1 functions as the hydrolase of ester bond between ADPR unit and Glu residue in both MARylated 
protein and PARylated protein. Micro D1/2 hydrolyzes the ester bond of MARylated protein as TARG1 does. The second type of hydrolase is the glycosidic bond hydrolase, such as ARH3 which is similar to aforementioned PARG and possesses exo-glycohydrolase activity. The third type of hydrolase is pyrophosphate bond hydrolase, such as ENPP1, NUDT9/16 and Snake venom phosphodiesterase mentioned in 2.1. The enzymatic hydrolysis of PARylated proteins by different enzymes is depicted in Figure 3B.

A
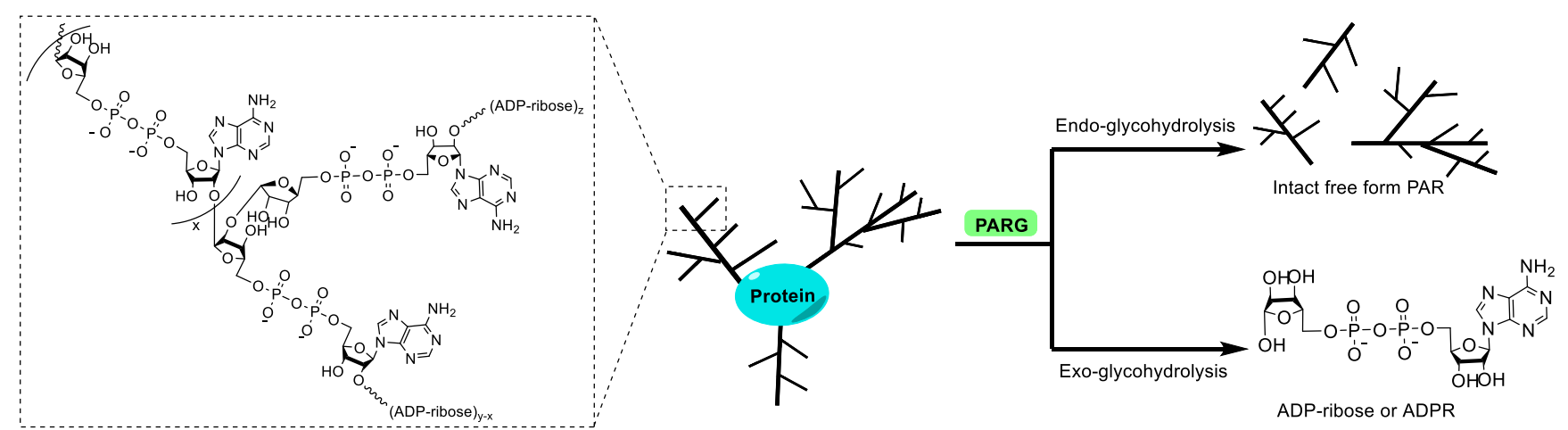

B

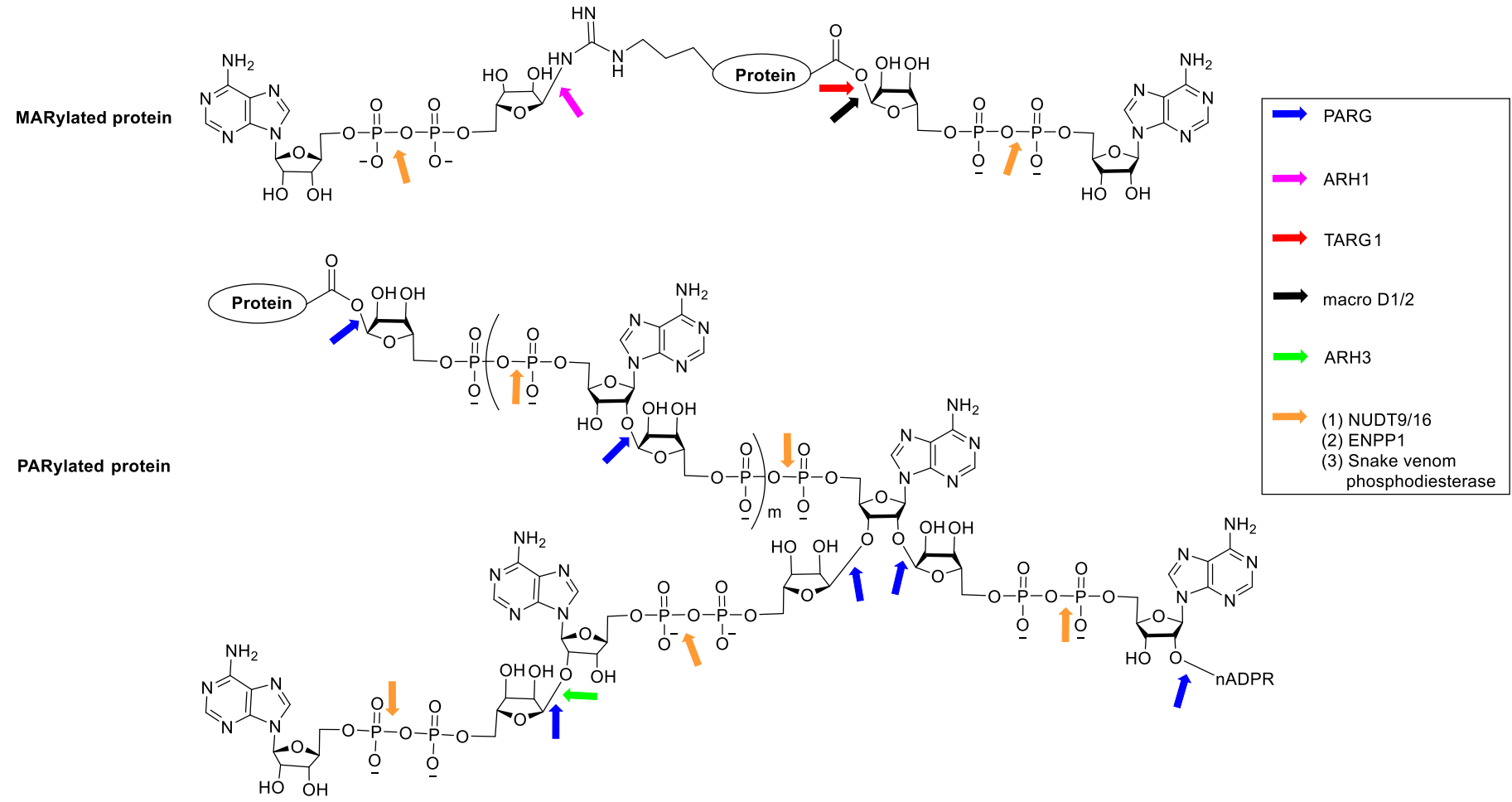

Figure 3. Hydrolysis of MARylated or PARylated proteins. PARG has both exo- and endo-glycohydrolase activities, which cleaves ribose-ribose $\alpha\left(2^{\prime}, 1^{\prime \prime}\right)$-glycosidic bond in the terminal position of PAR or glycosidic bond closed to acceptor, producing ADPR units and intact free form PARs, respectively (A). There are many identified enzymes (B) that hydrolyze different bonds of MARylated or PARylated proteins. Colored arrows represent the enzymatic hydrolysis sites.

\subsection{Poly(ADP-ribose) recognition of protein}

It is now well known that PAR influences many life processes of cell from two aspects. Firstly, PAR can be covalently modified onto nuclear proteins by linking with carboxylic or other nucleophilic amino acid 
residues. $^{6-9}$ Secondly, free PAR released from PARylated proteins, catalyzed by PARG, conversely regulates functions of acceptor proteins and non-covalently interacts with other proteins, ${ }^{44,51-55}$ resulting in the balance of PARylated protein/PAR ratio. However, disequilibrium of PARylated protein/PAR ratio may cause cell death. ${ }^{49}$ Some reports have revealed that the non-covalent interaction between PAR and proteins is in a PAR chain length-dependent manner. ${ }^{56}$ It is obvious that basic and hydrophobic amino acid residues are key factors for proteins to non-covalently bind to PAR. ${ }^{57}$

For the non-covalent PAR binding, several PAR recognition regions of protein have been found, including PAR-binding zinc finger (PBZ), PAR-binding motif (PBM), Trp-Trp-Glu (WWE) domain and macrodomain (Figure 4). ${ }^{9}, 47,49,58,59$ These regions are most likely to bind PAR through electrostatic interactions between the positively charged domains of acceptor proteins and the negatively charged phosphate groups of PAR, except for PBZ which may also bind PAR by zinc-adenine coordination bond. ${ }^{7}$

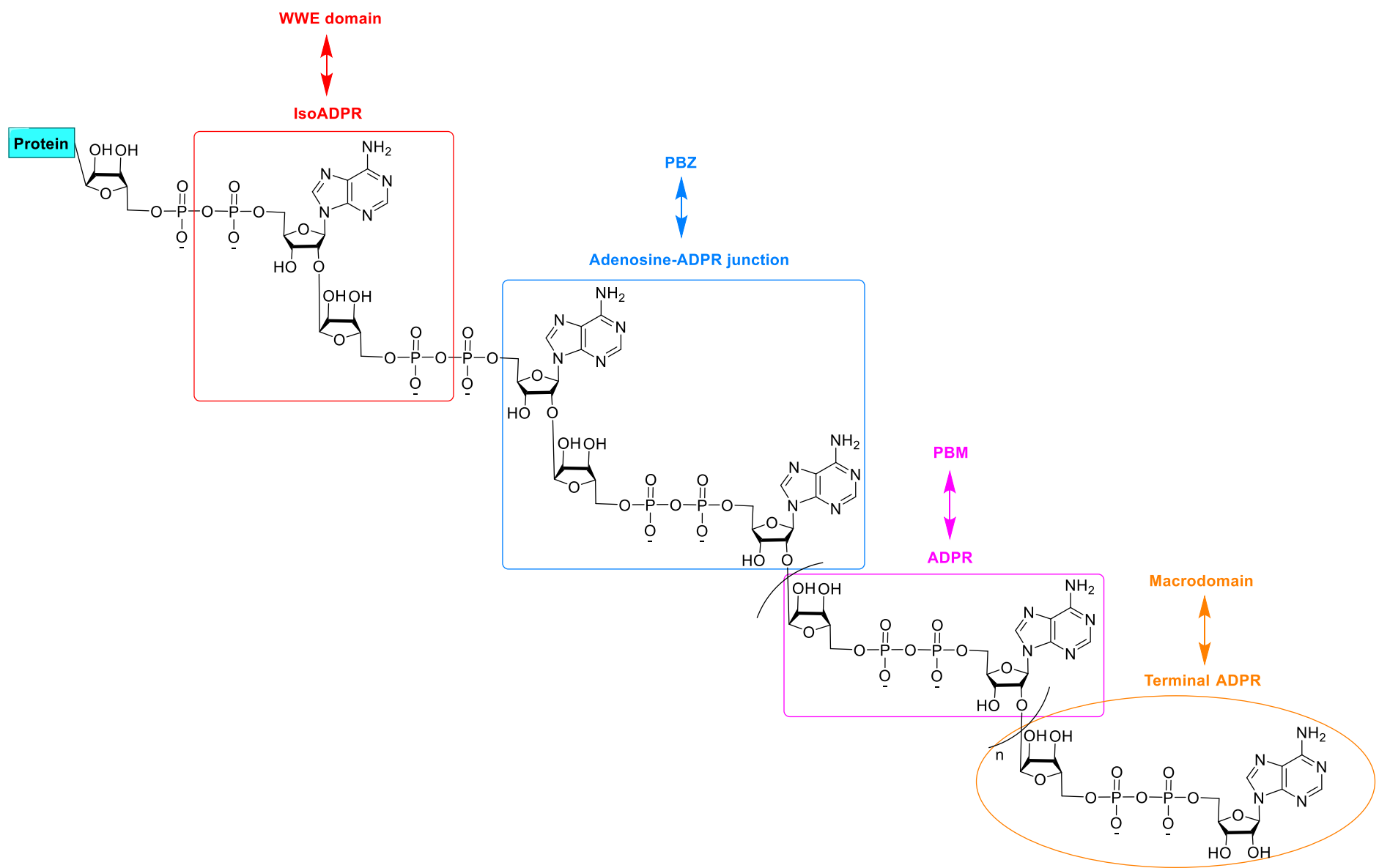

Figure 4. Non-covalent PAR binding regions of protein and their binding sites within PAR. Recognition sites: isoADPR for WWE domain; adenosine-ADPR junction for PBZ; ADPR for PBM and terminal ADPR for macrodomain.

\section{Synthesis of Poly(ADP-Ribose)}

\subsection{Enzymatic synthesis of poly(ADP-ribose)}

$\mathrm{NAD}^{+}$is an adenylate derivative with a small molecular weight of 662.42 , which functions as a coenzyme that is ubiquitous in many intracellular redox reactions. ${ }^{6,60}$ On the other hand, NAD ${ }^{+}$acts as the substrate of DNA 
damage-initiated protein PARylation. ${ }^{6-9} 17$ members have been found in PARP family, however, not all members have enzymatic activities. Kraus et al. classified PARPs into four subfamilies in their reviews, ${ }^{7}$ including: the DNA-dependent PARPs, such as PARP1, PARP2 and PARP3; the tankyrases, such as PARP5A and PARP5B; the Cys-Cys-Cys-His contained PARPs, such as PARP7, PARP12, PARP13.1 and PARP13.2; the macrodomian contained PARPs, such as PARP9, PARP14 and PARP15.

Enzymatically active PARPs have a $\mathrm{NAD}^{+}$-binding domain that binds the nicotinamide and $\mathrm{N}$-ribose fragments of $\mathrm{NAD}^{+}$in different orientations. ${ }^{7,}{ }^{61}$ As DNA damage occurs, nuclear localizing PARPs are recruited to the damage sites and $\mathrm{NAD}^{+}$is consumed as a donor of ADPR unit, releasing a nicotinamide and a proton and resulting in PARPs auto-PARylation (Figure 5). 6, 26,61 The first ADPR unit is covalently attached to protein by linking with carboxylic or nucleophilic amino acid residues. ${ }^{6-9}$ Subsequently, repeatedly adding ADPR units to the former synthesized PAR promotes the main chain to elongate. PAR chain that is elongating may branch every 20 to 50 ADPR units, catalyzing by PARPs with branching enzyme activities. ${ }^{6,7,62}$ The linkage between ADPR units both in main chain elongated and branched directions (Figure 1B) adopts $\alpha$-selective ribofuranosylation of adenosine (namely, the ribose-ribose $\alpha\left(2^{\prime}, 1^{\prime \prime}\right)$-glycosidic bond) (Figure 5)..$^{34}$

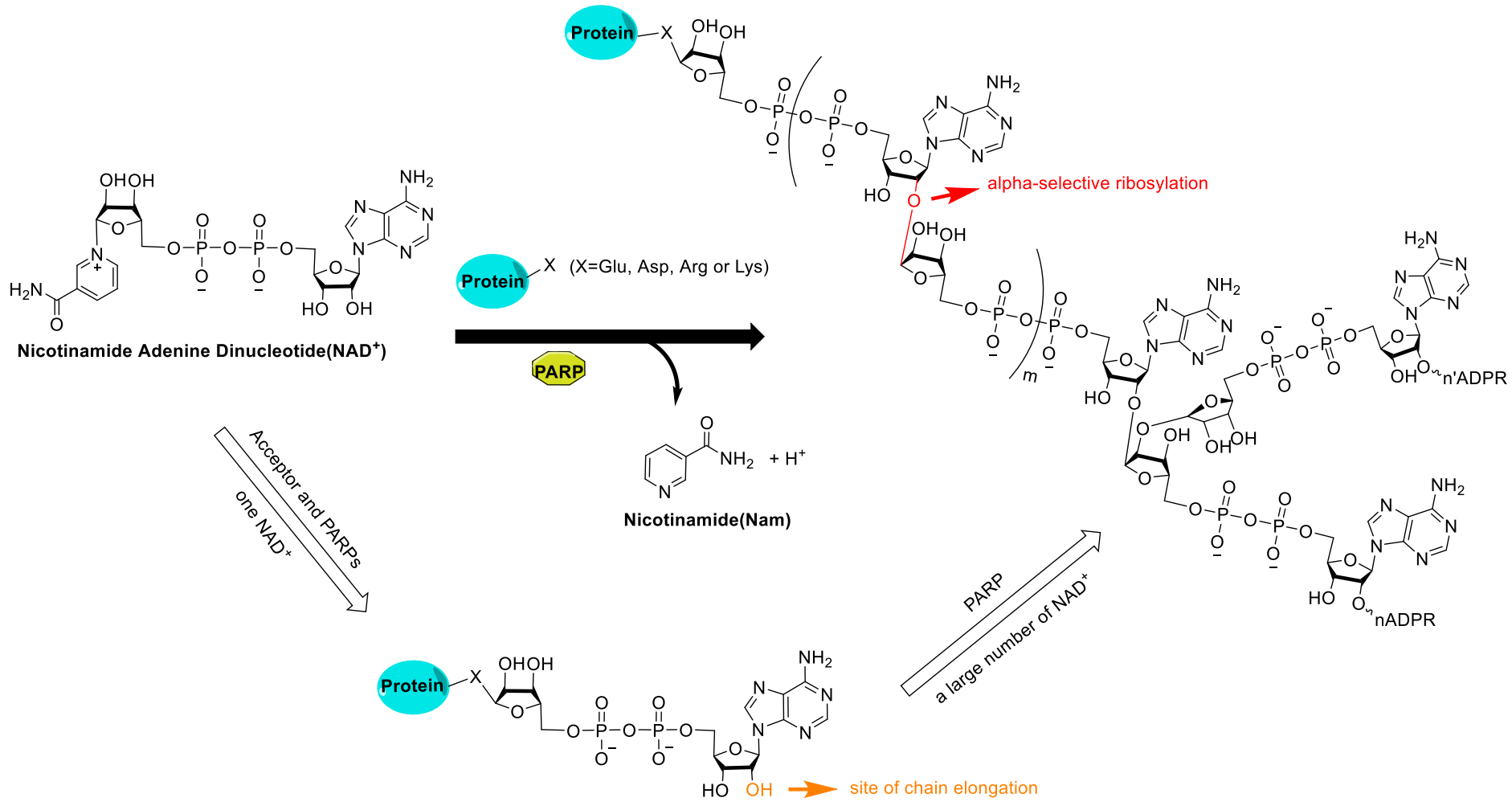

Figure 5. Process of enzymatic synthesis of PAR, in which NAD+ is used as a donor of ADPR unit. The route indicated by filled arrows represents the total reaction and the route indicated by hollow arrows represents stepwise reactions. $\alpha$-selective ribofuranosylation is adopted to elongate the chain of PAR, producing abundant dendritic PARs with high molecular weights.

Though it is the main enzyme for PAR synthesis, PAPR1 is non-specific to its substrate $\mathrm{NAD}^{+}$, making it possible to enzymatically synthesize PAR derivatives ${ }^{31}$ by utilizing three forms of modified $\mathrm{NAD}^{+}$that include base-modified derivative, ${ }^{29,63-65}$ nicotinamide-modified derivative ${ }^{65,66}$ and ribose-modified derivative. ${ }^{64}$ Marx et al. found that 2'-hydroxyl modified NAD analogues, picked from a series of modified $\mathrm{NAD}^{+}$compounds, could be promising to visualize the processes of PARP1 catalyzed intracellular PARylation. ${ }^{67}$ A small library of 
compounds that containined alkynyl modification, azide modification and alkenyl modification of $\mathrm{NAD}^{+}$, had been designed (1-10, Figure 6). Among these compounds, 4-10 were obtained according to the synthetic route given by Wallrodt's literature. ${ }^{67}$ Bioorthogonal chemical reactions, such as Copper(I)-mediated click reactions (CUAAC), strain-promoted azide-alkyne cycloaddition (SPAAC) and inverse electron demand Diels-Alder reactions $\left(D A_{i n v}\right)$, were thereby utilized for fluorescent labeling of PAR derivatives which were synthesized by PARPs through incorporating these NAD+ analogues into PAR skeleton in vitro.

Probes for CuAAC
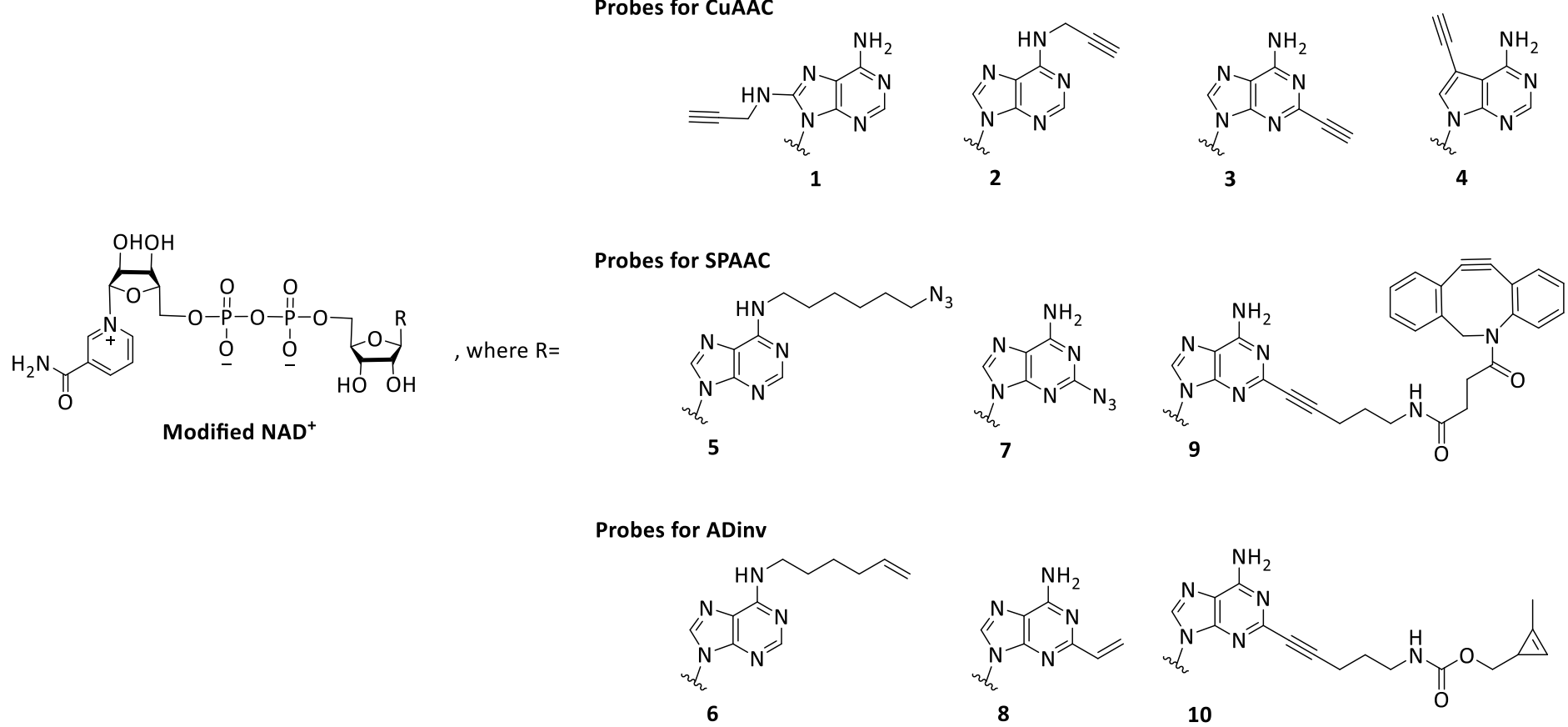

Figure 6. Structures of $\mathrm{NAD}^{+}$analogues 1-10 which can be used as probes for Copper(I)-mediated click reactions (CUAAC), strain-promoted azide-alkyne cycloaddition (SPAAC) and inverse electron demand DielsAlder reactions $\left(D A_{\text {inv }}\right)$, promising for fluorescent imaging of intracellular PARylation.

\subsection{Chemical synthesis of poly(ADP-ribose)}

It ought to be noted that enzymatic synthesis of PAR always generates a pile of compounds with different molecular weights and even with severe branching, waning the structural homogeneity of PAR. Multiple chromatographic purification steps are thus indispensable for enzymatic synthesis to prepare PAR. Therefore, chemical synthesis strategies may afford solutions to this issue because well-defined structure of PAR is available by exquisitely designing synthesis steps. Still, there are two key problems for chemical synthesis to be addressed: formation of disaccharide nucleoside with a ribose moiety connected to adenine by $\alpha\left(2^{\prime}, 1^{\prime \prime}\right)$ glycosidic bond and the formation of rather labile pyrophosphate bond. ${ }^{30,} 31,34$

3.2.1. Synthesis of disaccharide nucleoside. Disaccharide nucleosides constitute a widespread and important group of natural compounds, ${ }^{38,39,68}$ which have been isolated from Streptomyces $s p .{ }^{69}$ yeast RNA hydrolyzates ${ }^{68}$ and marine organisms. ${ }^{70,71}$ Disaccharide nucleosides exist not only in free state, but also as the components of bioacitve molecules such as tRNA ${ }^{72}$, antibiotics and PAR. ${ }^{68}$ The common structural feature of disaccharide nucleosides is that they all have extra pyranose or furanose moiety connected to nucleoside at 2' , 3'- or 5'-OH. In general, there are two routes that can be used to synthesize disaccharide nucleosides (Scheme 1). ${ }^{38,68}$ The first route is the coupling of the protected disaccharide with purine, pyrimidine or purine/pyrimidine derivatives. Another route is $O$-glycosylation of nucleoside, resulting in the generation of $O$ - 
glycosidic bond between nucleoside containing a free hydroxyl group and pre-activated monosaccharide. Both of the two routes undergo an intermediate of oxonium ion after $X$ leaving, that determines the transconfiguration of nucleophilic fragment relative to the OR group at C1 site (Scheme 1). It is important that proper route must be selected to prepare disaccharide nucleosides because different reaction sequences or conditions may engender distinct configurations of products. Besides, much attention should be paid to the protective groups under various coupling conditions, so that stable estimation of hydroxyl protection and stereoselective formation of glycosidic bonds can be successfully achieved.
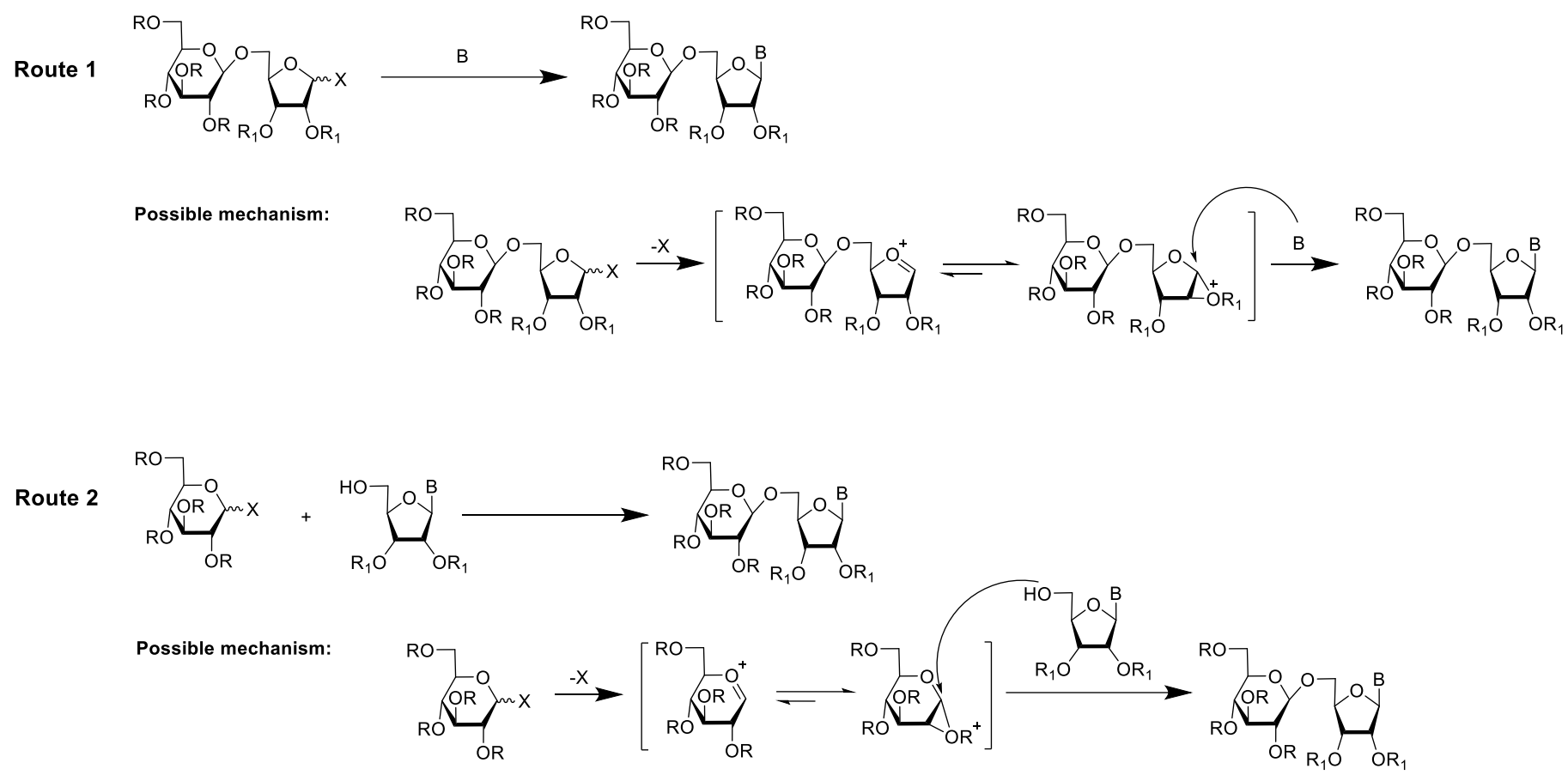

$\mathrm{B}=$ purine, pyrimidine, purine/pyrimidine derivatives

$X=\mathrm{Hal}, \mathrm{OAcyl}, \mathrm{SPh}$, etc.

Scheme 1. There are two routes for the synthesis of disaccharide nucleosides.

Two challenging aspects for disaccharide nucleoside synthesis are inevitable. Firstly, the configuration of $O$-glycosidic bonds including $\alpha$ - and $\beta$-anomers should be controllable. Secondly, selective protection and deprotection of hydroxyl groups must be taken into consideration. Some strategies have been taken to solve these posers. Mikhailov et al. utilized the Markiewicz blocking group (namely, the $\left(\mathrm{ClSi}^{i} \mathrm{Pr}_{2}\right)_{2} \mathrm{O}$ reagent was used) to concurrently protect $3^{\prime}-$ and $5^{\prime}-\mathrm{OH} .{ }^{73-75}$ They also adopted Robins oxidation-reduction sequence to inverse the configuration of 2'"-OH. Filippov et al. also used the Markiewicz blocking group for 3'- and 5'protection in the synthesis of disaccharide nucleoside building block of PAR oligomers. ${ }^{76}$ Marx et al. synthesized a pool of disaccharide nucleoside analogues by Mikhailov's method. ${ }^{77}$ Then they found that some of these analogues showed inhibitory effects on human PARP1 in vitro. ${ }^{77}$ Boronic acid has a high affinity with hydroxyl groups, Aoki et al., therefore, realized the regioselective 5'-O-glycosylation of nucleosides by transient protection of $2^{\prime}, 3^{\prime}$-diol using a boronic ester. ${ }^{78,79}$ In general, benzyl protection of hydroxyl groups on the ribofuranosyl donor in glycosylation reaction enables production of $\alpha$-glycosidic bond. This $\alpha$-selective fashion can be explained by nucleophilic attack on the five-membered oxocarbenium ion which may be an active intermediate in the nucleophilic substitution reaction. In contrast, acyl protection of hydroxyl groups 
exclusively forms $\beta$-glycosidic bond owing to neighboring group participation. Besides, 2,3-isopropylidene or 2,3-benzylidene protection of hydroxyl groups is likely to generate a mixture of $\alpha$ - and $\beta$-anomers. ${ }^{76}$

Many synthetic methods of disaccharide nucleosides have been summarized in some reviews. ${ }^{38-40,68}$ Here, we mainly focus on the synthetic tactics of protected disaccharide nucleosides which are the key building blocks for the chemical synthesis of PAR. Currently, route 2 (Scheme 1) has been increasingly applied to prepare protected 2'-O- $\alpha$-D-ribofuranosyladenosine (11, Scheme 2$)$, and the construction of this building block determines PAR synthesis efficiency. The chemical synthesis of 2'-O- $\alpha$-D-ribofuranosyladenosine was firstly developed by Mikhailov et al. in 2008, using 3',5'-O-protected adenosine (12) and 1-O-acetyl-2,3,5-tri-Obenzoyl-D-arabinofuranose $(\mathbf{1 3})$ as starting materials. ${ }^{73}$ The approach was later opted to prepare $2^{\prime}-O-D-$ ribofuranosyluridine. ${ }^{75}$ Under the catalysis of the Lewis acid $\mathrm{SnCl}_{4}$ at $0{ }^{\circ} \mathrm{C}, 14$, containing $2^{\prime}-O$ - $\alpha$-glycosidic bond, was easy to generate from the reaction between 12 and 13 . The neighboring participation of 2-OBz group in compound 13 mediated 1,2-trans-selective coupling of 13 with protected adenosine, leading to the formation of 1",2"-trans-ribofuranosyladenosine (compound 14). The Markiewicz blocking group was used to replace benzoyl group at $35{ }^{\circ} \mathrm{C}$ after selective benzoyl deprotection (compound 15 ) in $\mathrm{MeONa} / \mathrm{MeOH}$ solution, yielding product 16 . Then, configurational inversion of 2 "- $\mathrm{OH}$ was accomplished by oxidation in the solution of $\mathrm{DMSO} / \mathrm{AC}_{2} \mathrm{O}$ and reduction by $\mathrm{NaBH}_{4}$ reagent, forming product 18 containing $1^{\prime \prime}, 2^{\prime \prime}$-cis-ribofuranosyl adenosine. Finally, $\mathrm{NH}_{3} / \mathrm{MeOH}$ and tetrabutyl ammonium fluoride (TBAF) were separately used to remove benzoyl group and the Markiewicz blocking group of $\mathbf{1 8}$ and $\mathbf{1 4}$ at mild condition, yielding compound 11 and 19, respectively. The major deficiencies of this tactic lie in the low yield and the rather long reaction time of benzoyl deprotection, leading to insufficient universality.

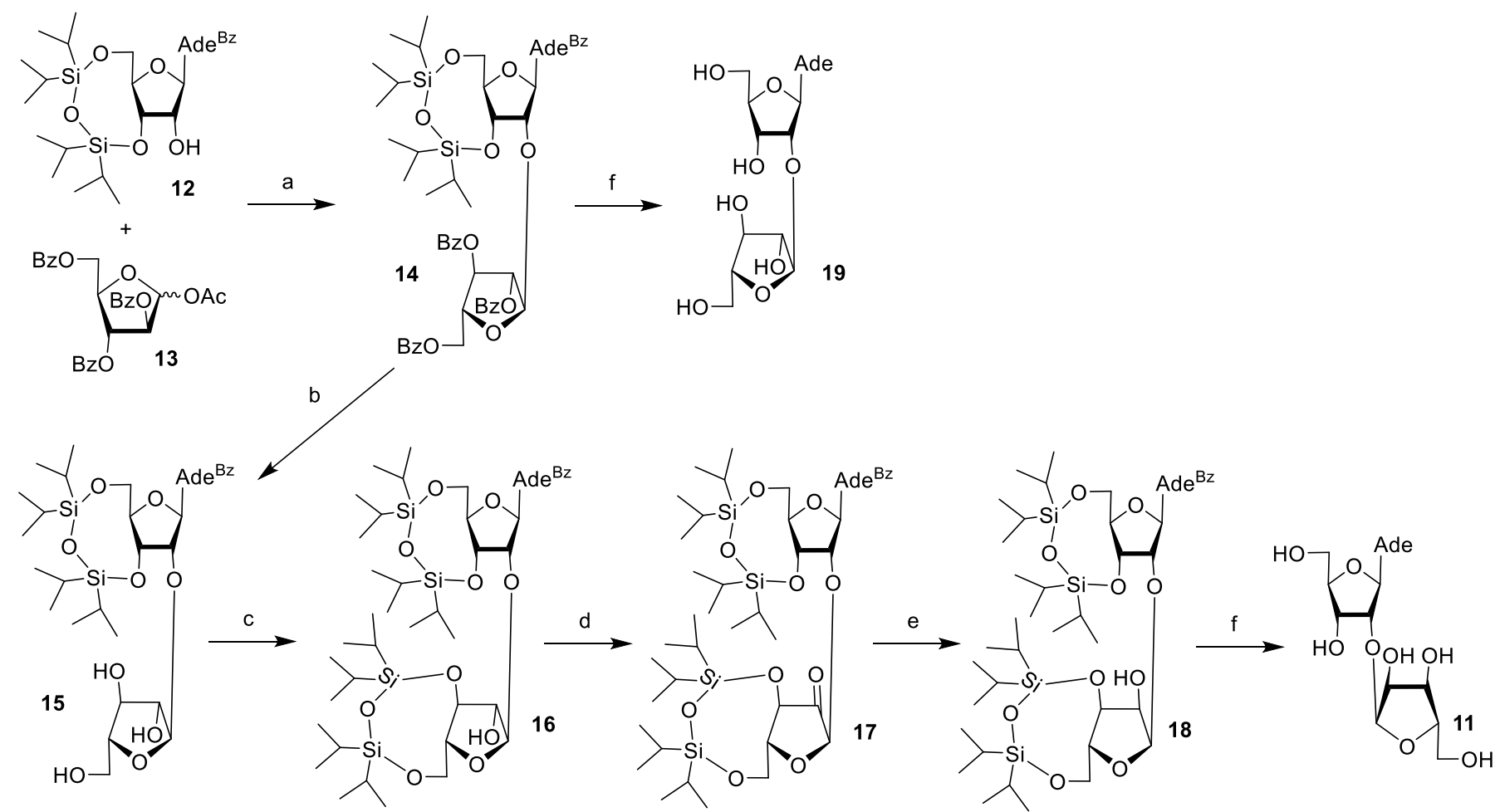

Scheme 2. The first chemical synthesis approach of 2'-O- $\alpha$-D-ribofuranosyladenosine (11), developed by Mikhailov et al.. ${ }^{73}$ Reaction conditions: a) $\mathrm{SnCl}_{4}, \mathrm{ClCH}_{2} \mathrm{CH}_{2} \mathrm{Cl}, \mathrm{N} 2$; b) $0.1 \mathrm{M} \mathrm{MeONa} / \mathrm{MeOH}$; c) $\left(\mathrm{ClSi}^{i} \mathrm{Pr}_{2}\right)_{2} \mathrm{O}$, pyridine; d) DMSO, $\mathrm{Ac}_{2} \mathrm{O}$; e) $\mathrm{NaBH}_{4}, \mathrm{EtOH}$; f) i. $\mathrm{NH}_{3} / \mathrm{MeOH} ;$ ii. $\mathrm{Bu}_{4} \mathrm{NF} \bullet 3 \mathrm{H}_{2} \mathrm{O}$, THF. 
Considering the fact that disaccharide nucleoside fragments in PAR uniquely bear $\alpha$-glycosidic bonds, a suitable and orthogonal protecting group tactic that generates products with accurate configuration via $O$ glycosylation reaction between ribofuranosyl donors and acceptors, is urgently demanded. Filippov et al. found that imidate compound $\mathbf{2 1}$ (Scheme 3) was an efficient ribofuranosyl donor which was nucleophilically attacked by the unprotected hydroxyl group of $\mathbf{2 2}$ in the presence of TMSOTf through the mechanism of bimolecular nucleophilic substitution reaction $\left(S_{N} 2\right)$, forming the expected product $\mathbf{2 3}$ containing $\alpha$-glycosidic linkage. ${ }^{76}$ From the reaction of 2,3,5-tri-O-Bn-ribose (20) with $\mathrm{Cl}(\mathrm{C}=\mathrm{NPh}) \mathrm{CF}_{3}, 21$ was prepared with a yield of $92 \%$. In order to avert $\mathrm{N}$-glycosylation, amino group of adenosine $\mathbf{2 2}$ was caged by two benzoyl groups. For deprotective reactions, palladium or $\mathrm{BCl}_{3}$ was selected to catalyze the benzyl removal. $\mathrm{NH}_{3} / \mathrm{MeOH}$ was utilized to completely remove the benzoyl protection. Nevertheless, $\mathrm{MeNH}_{2}$ could only partially deprotect adenosine, generating $\mathbf{2 5}$ with single benzoyl protected amino group. TBAF could solely eliminate organosilicon protection and was used to remove the Markiewicz blocking group. Unfortunately, the overall yield of the deprotective reactions was undesired. Compound 24-26 were obtained after deprotecting hydroxyl or amino groups. Finally, fully orthogonal protected building block 28 was prepared with a moderate yield for further synthesis of PARylated peptides. ${ }^{76}$

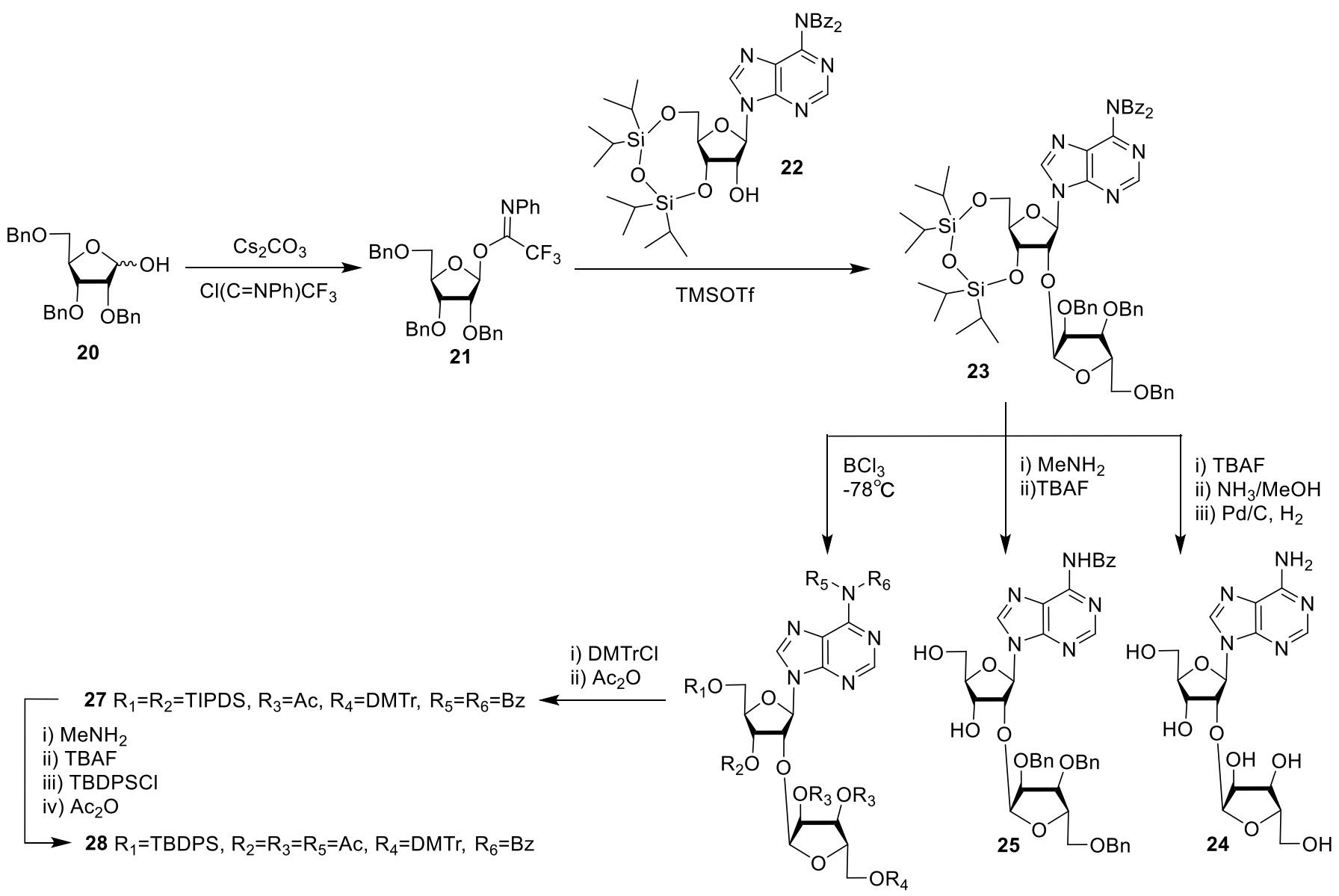

$26 \mathrm{R}_{1}=\mathrm{R}_{2}=$ TIPDS, $\mathrm{R}_{3}=\mathrm{R}_{4}=\mathrm{OH}, \mathrm{R}_{5}=\mathrm{R}_{6}=\mathrm{Bz}$

Scheme 3. Imidate $\mathbf{2 1}$ was utilized as ribofuranosyl donor for $\alpha$-selective $O$-glycosylation of adenosine. The final product $\mathbf{2 8}$ was introduced with orthogonal protective groups.

To simulate the authentic structure, construction of the core motif of branched PAR, trisaccharide nucleosides, should hence be taken into consideration. This is a more challenging task because it includes two 
$\alpha$-selective glycosylation sites. Gratifyingly, many attempts have been made by Filippov lab. ${ }^{80,81}$ Their strategy has proclaimed success for chemical construction of trisaccharide nucleosides of branched PAR.

3.2.2. Synthesis of the pyrophosphate linkage. Mono- or multi-phosphorylation (including di- and triphosphorylation) is required for intracellular synthesis of nucleotides, nucleic acids and their derivatives which are converted from nucleosides in the presence of kinases. ${ }^{82}$ To date, many approaches of converting alcohols into their phosphate esters have been fabricated by exerting inorganic phosphorylation reagents, such as white phosphorus, ${ }^{83}$ phosphoric acid ${ }^{83}$ and $\mathrm{POCl}_{3} .84,85$ These reactions need amines as organic bases or organic ammonium salts as catalysts, and some reactions even take place under hostile conditions, such as rather high temperature. On the other hand, yields of these reactions are always undesired. Nevertheless, very few methods have been developed for multi-phosphorylation of alcohols that contains more than three phosphorus atoms. ${ }^{86,87}$

Besides, organic phosphorylation reagents, including 2-cyanoethyldiisopropylphosphoramidochloridite and cyanoethyl P-imidazolides, are also utilized to form mono- or multi-phosphate esters. ${ }^{88,89}$ The use of 2cyanoethyldiisopropylphosphoramidochloridite should avoid humid environment and oxidants. A striking feature for multi-phosphate compounds is that phosphate bonds with high energy are quite easy to hydrolyze, resulting in low yields and difficulties in purification and storage. Conventional methods for phosphate ester formation have suffered from some problems. For example, the poor solubility of intermediates and products brings about a need of unamiable solvents such as dichloromethane, tetrahydrofuran and $N, N$ dimethylformamide; phosphorylation reagents should be prepared in advance under oxygen-free and dry environment; multitudinous protective and deprotective reactions with extensive purification procedures generate low overall yields.

For multi-phosphorylation, such as diphosphorylation and triphosphorylation, two strategies have been developed and are used frequently (Scheme 4). The first strategy is the coupling of alcohol with pre-prepared multi-phosphitylation reagent, followed by oxidation reaction that converts the phosphorus species from $\mathrm{P}$ (III) to $\mathrm{P}(\mathrm{V})$. Parang et al. reported a solid-phase strategy for multi-phosphitylation reagents construction which were used for multi-phosphorylation of nucleosides and saccharides (Scheme 4C). ${ }^{88}, 90$ Compared to liquidphase strategy (Scheme 4B), solid-phase strategy led to simplified purification processes of intermediates and products. First of all, compounds $\mathbf{3 2}$ and $\mathbf{3 3}$ were prepared in the absence of any base via method illustrated in Scheme $4 \mathrm{~A}^{88} \mathrm{PCl}_{3}$ was selected as the source of phosphorus and reacted with 3-hydroxypropionitrile forming the water-labile compound 29. Diisopropylamino group was used to temporarily protect trivalent phosphorus (compound 30), which could be removed by nucleophilic substitution of alcohols under the catalysis of $1 \mathrm{H}$ tetrazole. Then, solid-phase synthesis of multi-phosphitylation reagents (Scheme 4C) was performed onto aminomethyl polystyrene resin in multiple steps. The hindered resin-bound multi-phosphitylation reagents selectively reacted with the most reactive hydroxyl group of nucleosides or saccharides. Trivalent phosphorus was oxidized by either $\mathrm{tBuOOH}$ or $3 \mathrm{H}-1,2-$ benzotrithiole-3-one-1,1-dioxide (Beaucage's reagent), affording multi-phosphate (46a-h and 47a-h) or multi-thiophosphate (46'a-h and 47'a-h). 1,8-diazabicyclo[5.4.0] undec7-ene (DBU) was used to remove the protective groups of $\mathrm{P}-\mathrm{O}$ bonds and final products were collected by cleaving it from resin beads with TFA/DCM/ $\mathrm{H}_{2} \mathrm{O}$ solution. The liquid-phase synthesis illustrated in Scheme $4 \mathrm{~B}$ is more complicated though synthesis of multi-phosphitylation reagents can also be realized. ${ }^{90}$ In 2007 , Parang et al. used their solid-phase method (Scheme 4C) to successfully synthesize a group of modified oligodeoxynucleotides bearing pyrophosphate linkages. ${ }^{91}$

The second strategy for diphosphorylation of alcohols is the coupling of unprotected hydroxyl group of monophosphates with trivalent phosphitylation reagents, ${ }^{34}$ which can be referenced from a work of Filippov $\mathrm{lab}^{92}$ and a review paper ${ }^{93}$ and will be described in part 3.2.3. 
B

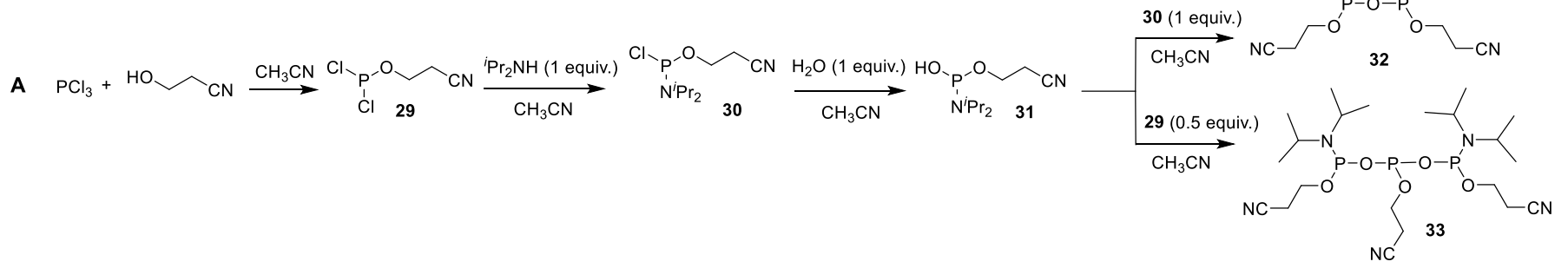
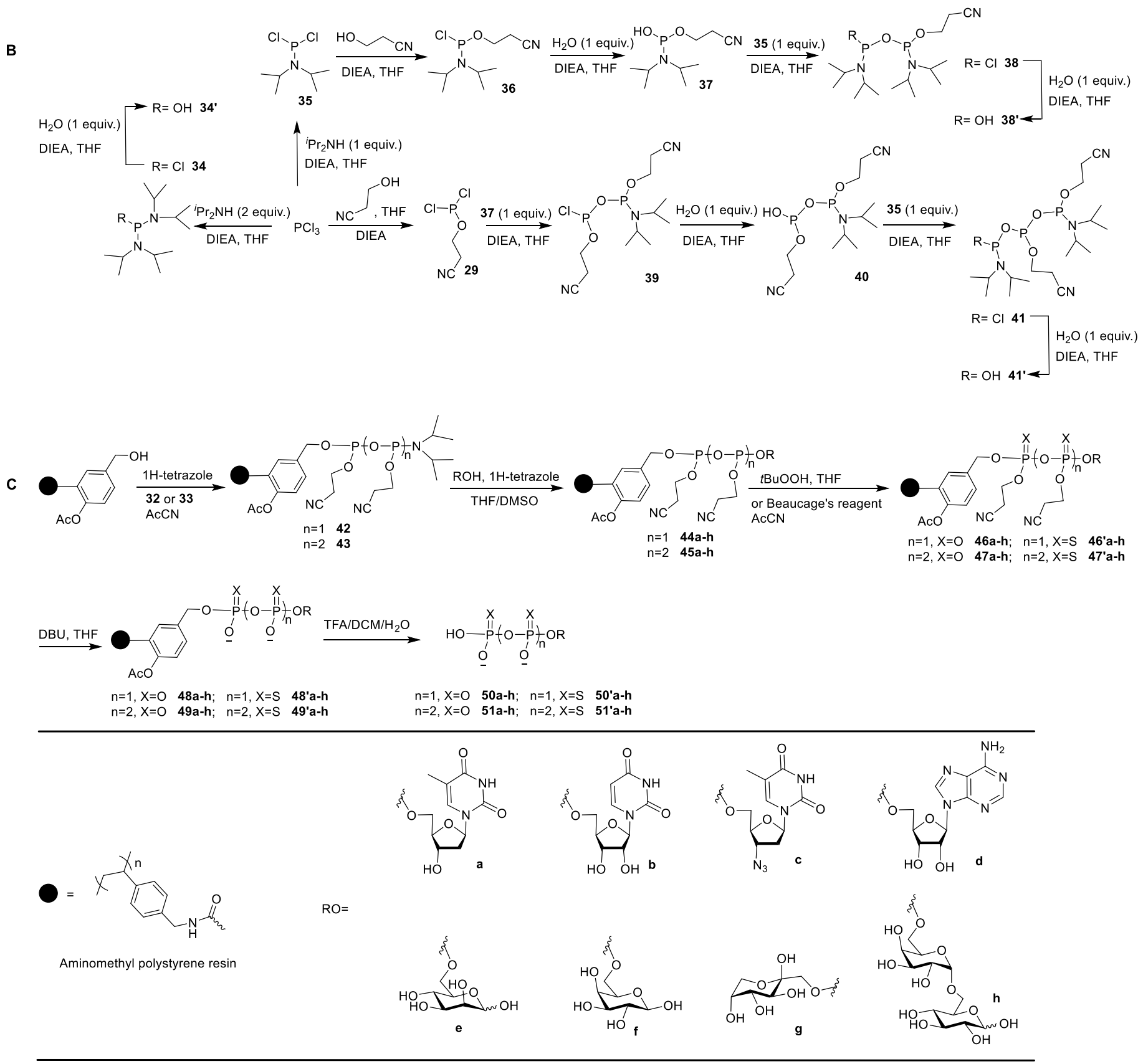

Scheme 4. Multi-phosphitylation reagents were prepared by liquid-phase (B) or Solid-phase method (C). Compared to liquid-phase method, solid-phase method, based on compound 32 and 33 (A), is beneficial to simplify purification of intermediates and products. 
3.2.3. Synthesis of poly(ADP-ribose). PARylation is a universal post-translational modification of nuclear proteins and mediates numerous intracellular processes. Thus, chemical synthesis may be a powerful strategy for construction of PARylated peptides and free oligo(ADP-ribose) molecules which are conducive to the research of cellular signalings involving PARylation. Since there have been some breakthroughs for construction of disaccharide nucleosides and pyrophosphate linkages, chemical synthesis of PAR is no longer out of reach. We here do not emphasize the synthesis of MARylated or PARylated peptides, though there are exactly some instances. ${ }^{30,92,93}$ We intend to focus on the synthesis of free PAR molecules by giving several examples.

In 2015, Filippov et al. reported their solid-phase synthetic strategy of ADP-ribose oligomers, which was considered as the first case of chemical synthesis of di- and tri(ADP-ribose). ${ }^{34}$ By inverse synthesis analysis (Scheme 5), the skeleton of PAR with repeated ADPR units could be divided into three parts: (1) the initial ribose $5^{\prime \prime}$-phosphate fragment; (2) the disaccharide nucleoside $5^{\prime}, 5^{\prime \prime}$-diphosphate fragment; (3) the terminal adenosine 5'-phosphate. Each fragment should be separately synthesized in advance, and then these synthesized fragments $(\mathbf{6 8}, 71$ and 72 ) could be further integrated into an entire PAR molecule (Scheme 6C). Thus, a pressing matter of the synthesis is to prepare these fragments with just correct protective groups.
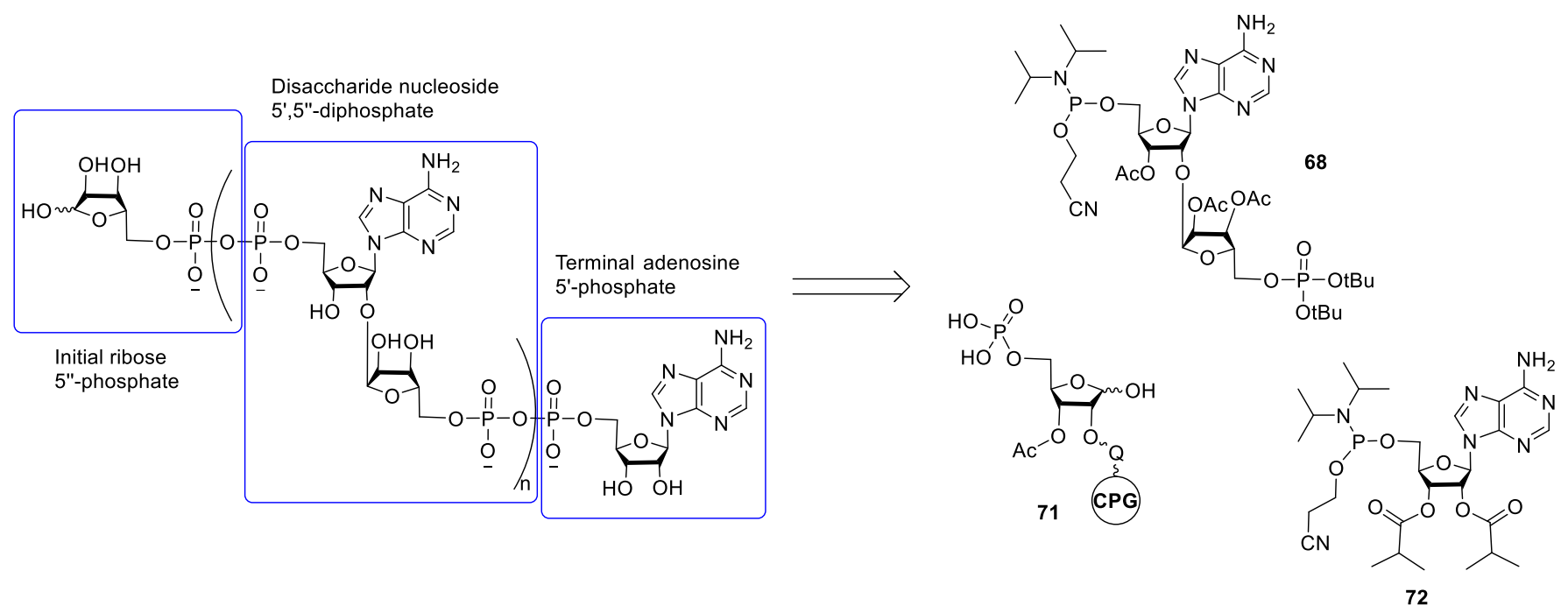

Scheme 5. The skeleton of PAR molecule can be divided into three parts by inverse synthesis analysis given by Filippov et al.

Inspired by their research in 2011, ${ }^{76}$ Filippov et al. used imidate compound $\mathbf{5 9}$ (Scheme 6A), synthesized in several steps with a considerable yield, as ribose donor to ribosylate 2 '-hydroxyl of adenosine in an $\alpha$ selective fashion. ${ }^{94}$ However, the most challenging work was the preparation of compound 68 (Scheme 5 and 6B) which was a key building block for PAR synthesis. The coupling of 59 with 1,3,5-tri-O-benzoylribose (60) at low temperature yielded protected disaccharide 61 (Scheme 6B). With benzyl group replaced by acetyl group, benzoyl protected adenine was added to the five-membered ribose (compound 63), catalyzed by $\mathrm{HClO}_{4}-\mathrm{SiO}_{2}$. Subsequently, disaccharide adenosine 65 was generated after protecting group replacement and removal of triisopropylsilyl group. $(t \mathrm{BuO})_{2} \mathrm{PN}^{\prime} \mathrm{Pr}_{2}$ reagent was used to phosphorylate the $5^{\prime \prime}$-hydroxyl group of 65 , followed by oxidation with $t \mathrm{BuOOH}$, yielding compound 66. Finally, phosphoramidite group was fixed on the $5^{\prime}$ hydroxyl group after selectively eliminating DMTr group under a solution of $1 \%(\mathrm{v} / \mathrm{v})$ trifluoroacetic acid (TFA) in $\mathrm{CH}_{2} \mathrm{Cl}_{2}$. Thus far, the building block 68 was acquired by 10 reaction steps in an overall yield of $19 \%$. The resin 
CPG with alkyl amine chains was selected as the solid support which loaded ribose 5-phosphate (71) by a DBU-resistant linker, hydroquinone-O,O'-diacetic acid (the " $\mathrm{Q}$ " linker, Scheme 6C). ADP-ribose oligomers were then programmatically prepared by an automated oligonucleotide synthesizer. Degree of polymerization of ADP-ribose oligomers depended on the adding times (the " $n$ " value) of the building block 68. Ultimately, the dimer $\mathbf{7 4}$ and trimer $\mathbf{7 5}$ were gotten in considerable yields of $35 \%$ and $29 \%$, respectively.
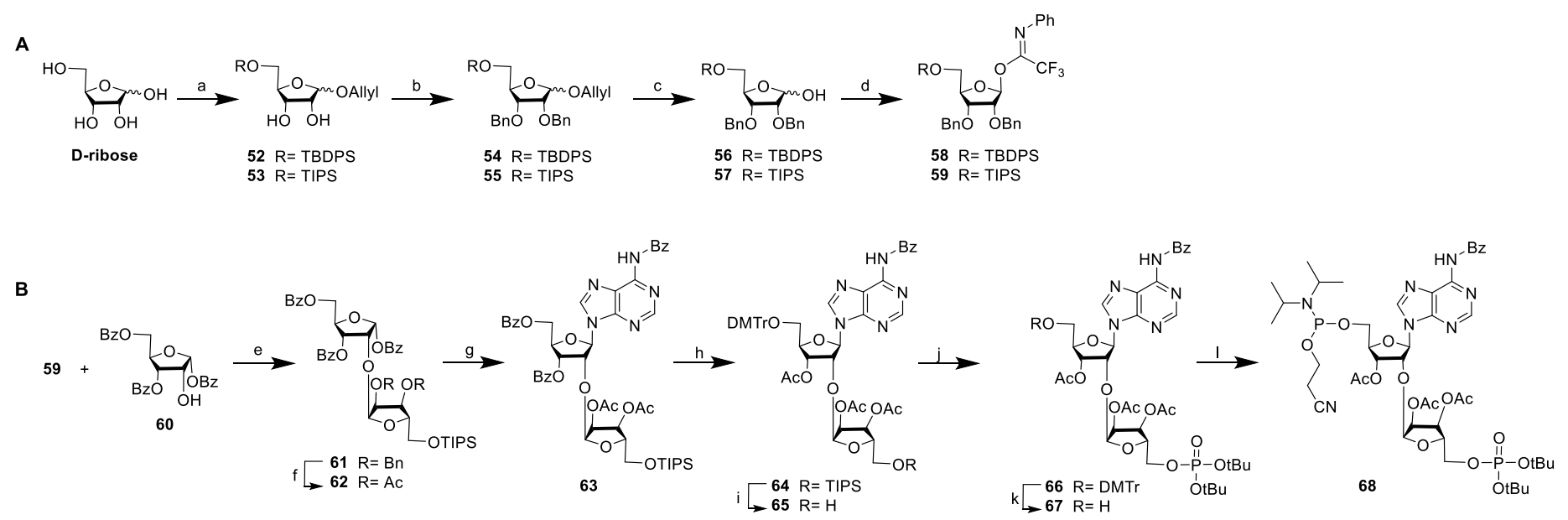

c

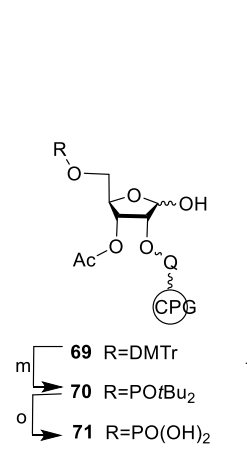

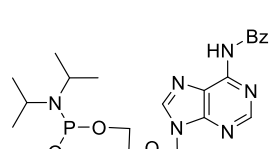
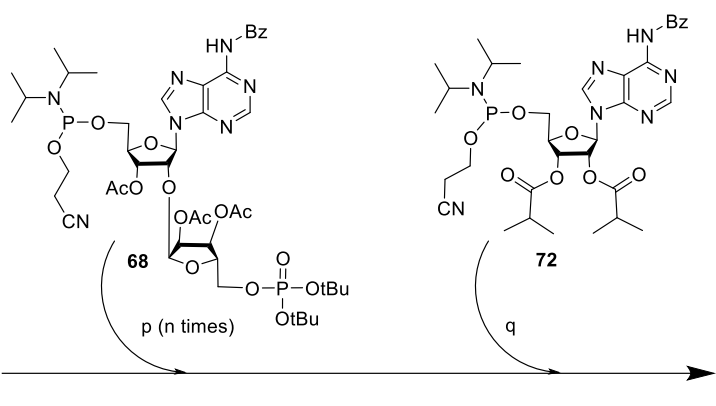

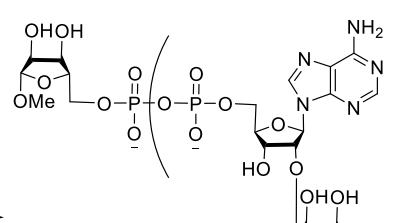

$73 n=0$, ADP-ribose $74 n=1$, di(ADP-ribose)
$75 n=2$, tri(ADP-ribose)

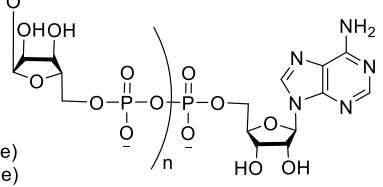

Scheme 6. Synthesis of active imidate compound 59 (A) and building block 68 (B) which are used for solidphase synthesis of ADP-ribose oligomers (C). Reaction conditions: a) i. Allyl-OH, acetyl chloride; ii. RSiCl, imidazole, DMF; b) $\mathrm{BnBr}, \mathrm{NaH}, \mathrm{DMF}$; c) i. 3 mol\% $\operatorname{Ir}(\mathrm{COD})\left(\mathrm{Ph}_{2} \mathrm{MeP}_{2} \mathrm{PF}_{6}, \mathrm{H}_{2}\right.$, THF; ii. aq. $\mathrm{NaHCO}_{3}$ (sat.), $\mathrm{I}_{2}$; d) $\mathrm{Cl}(\mathrm{C}=\mathrm{NPh}) \mathrm{CF}_{3}, \mathrm{Cs}_{2} \mathrm{CO}_{3}$, acetone; e) 1 mol\% TMSOTf, $\mathrm{CH}_{2} \mathrm{Cl}_{2} ;$ f) i. $\mathrm{H}_{2}, \mathrm{Pd} / \mathrm{C}, t \mathrm{BuOH} /$ dioxane/ $\mathrm{H}_{2} \mathrm{O} ; i$ i. Ac $\mathrm{C}_{2} \mathrm{O}$, pyridine; g) $\mathrm{HClO}_{4}-\mathrm{SiO}_{2}$, MeCN, BSTFA, $\mathrm{N}^{6}$-benzoyladenine; h) i. pyridine/EtOH/NaOH (1 M) (3:2:3, v/v/v); ii. pyridine, DMTrCl; iii. pyridine, $\mathrm{Ac}_{2} \mathrm{O}$; i) $\mathrm{Et}_{3} \mathrm{~N} \cdot 3 \mathrm{HF}, \mathrm{Et}_{3} \mathrm{~N}$, pyridine; j) i. (tBuO) ${ }_{2} \mathrm{PN}^{i} \mathrm{Pr}_{2}, 1-\mathrm{Me}-\mathrm{Im} \cdot \mathrm{HCl}(0.3 \mathrm{M}), 1-\mathrm{Me}-$ Im (0.2 M), DMF; ii. tBuOOH; k) TFA(1\%, v/v), $\mathrm{CH}_{2} \mathrm{Cl}_{2}$; I) 2-cyanoethyl N,N-diisopropyl chlorophosphoramidite, DIPEA, $\left.\mathrm{CH}_{2} \mathrm{Cl}_{2} ; \mathrm{m}\right)$ i. TFA (5\%, v/v), $\mathrm{CH}_{2} \mathrm{Cl}_{2}$; ii. (tBuO) ${ }_{2} \mathrm{PN}^{i} \mathrm{Pr}_{2}$, 1-Me-Im·HCl (0.3 M), 1-Me-Im (0.2 M), DMF; iii. CSO, MeCN; o) i. TFA (10\%, v/v), $\mathrm{CH}_{2} \mathrm{Cl}_{2}$; ii. pyridine/ $\left.\mathrm{H}_{2} \mathrm{O}(9: 1, \mathrm{v} / \mathrm{v}) ; \mathrm{p}\right)$ i. compound 68, ETT MeCN (2x); ii. CSO, $\operatorname{MeCN}(2 \mathrm{x})$; iii. DBU, DMF, (2x); iv. HCl, HFIP (4x); v. pyridine (10\%, v/v), acetonitrile (2x); q) i. compound 72, ETT, MeCN (2x); ii. CSO, MeCN (2x); iii. DBU, DMF (2x); iv. $\mathrm{NH}_{4} \mathrm{OH}(35 \%) . \mathrm{Bn}=$ benzyl, TBDPS = tertbutyl diphenylsilyl, TIPS = triisopropylsilyl, BSTFA = N, O-bis(trimethylsilyl) trifluoroacetamide, $\mathrm{DMTrCl}=4,4$ ' dimethoxytrityl chloride, $\mathrm{Bz}=$ benzoyl, $\mathrm{DIPEA}=\mathrm{N}, \mathrm{N}$-diisopropyldiethylamine, $\mathrm{DMF}=\mathrm{N}, \mathrm{N}$-dimethylformamide, TMSOTf = trimethylsilyl trifluoromethane sulfonate, $\mathrm{CSO}=(1 \mathrm{~S})-(+)-(10$-camphorsulfonyl)-oxaziridine. 
In the same year, Hergenrother et al. described a liquid-phase synthetic strategy of the ADP-ribose dimer (Scheme 7C), contributing to obtainment of the first cocrystal structure of human PARG substrate-enzyme. ${ }^{95}$ They took inverse synthesis analysis and obtained three fragments similar to that of Filippov's (Scheme 7A). The adenosine monophosphate initiator $\mathbf{8 1}$, the ribose monophosphate terminator $\mathbf{7 8}$, the glycosyl acceptor $\mathbf{8 2}$ and the glycosyl donor $\mathbf{8 3}$ were prepared according to Hergenrother's method. ${ }^{95}$

A
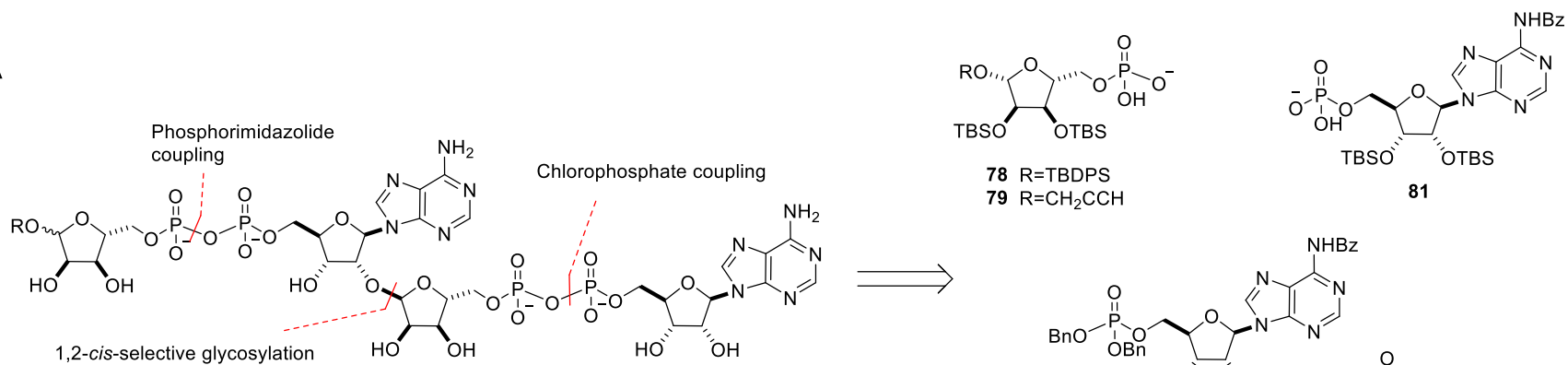

$79 \mathrm{R}=\mathrm{CH}_{2} \mathrm{CCH}$

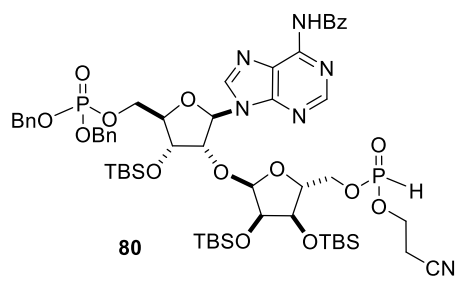

B
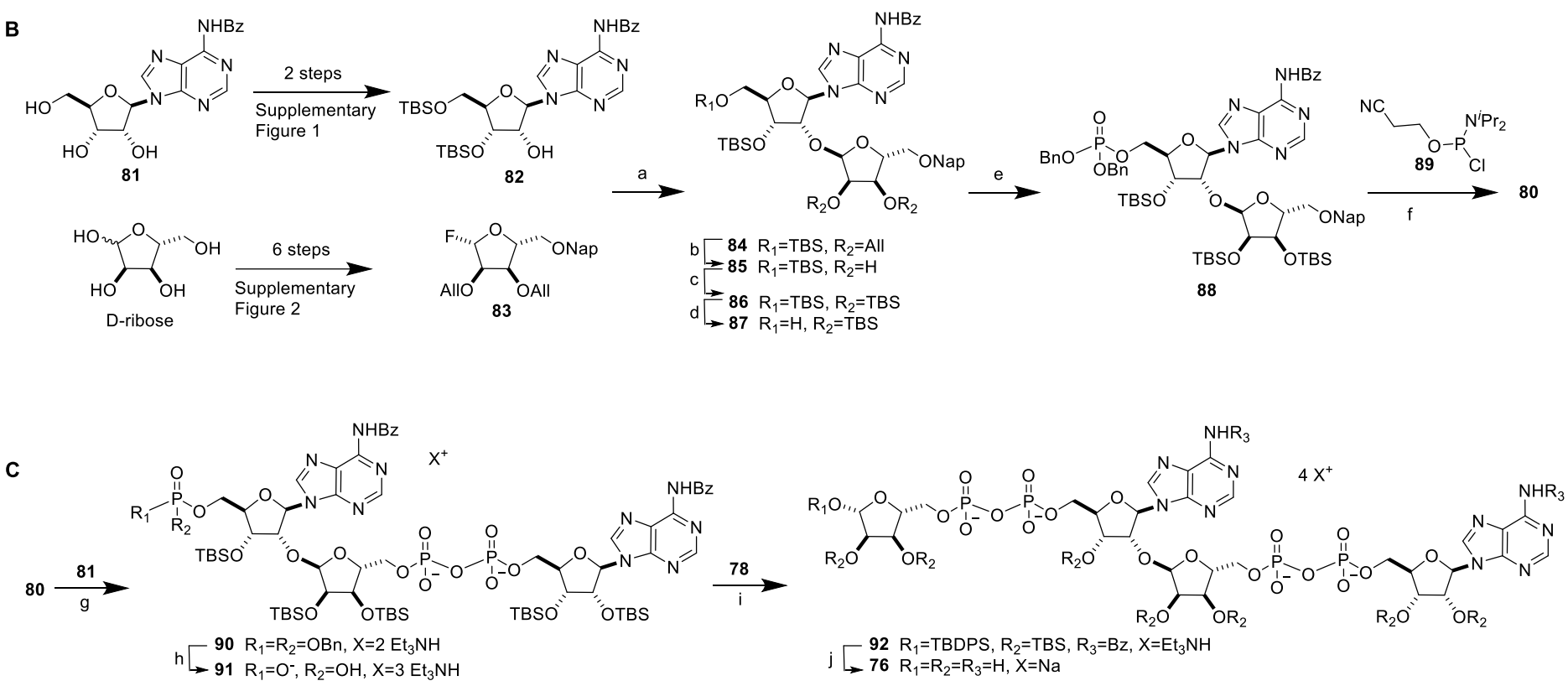

Scheme 7. A liquid-phase synthetic strategy of ADP-ribose dimer (76) reported by Hergenrother et al. (A) ${ }^{95}$ Inverse synthesis analysis of the dimer. (B) Synthesis of the building block $\mathbf{8 0}$. (C) Assembly process of the dimer. Reaction conditions: a) $\mathrm{SnCl}_{2}, \mathrm{AgPF}_{6}, 4 \AA \mathrm{AS}, \mathrm{CH}_{2} \mathrm{Cl}_{2}$; b) $\mathrm{Pd}\left(\mathrm{PPh}_{3}\right)_{4}(20 \mathrm{~mol} \%), \mathrm{N}, \mathrm{N}$-dimethylbarbituric acid, $\mathrm{MeOH}$; c) TBSOTf, DMAP, EtN ${ }^{i} r_{2}, \mathrm{CH}_{2} \mathrm{Cl}_{2}$; d) $\mathrm{CCl}_{3} \mathrm{CO}_{2} \mathrm{H}$, THF/ $\mathrm{H}_{2} \mathrm{O}(1: 1, \mathrm{v} / \mathrm{v})$; e) ${ }^{i} \operatorname{Pr}{ }_{2} \mathrm{NP}(\mathrm{OBn})_{2}, 4,5-$ dicyanoimidazole, $\mathrm{CH}_{2} \mathrm{Cl}_{2} / \mathrm{CH}_{3} \mathrm{CN}$ (4:1, v/v); then $t \mathrm{BuOOH}$; f) i. DDQ, $\mathrm{CH}_{2} \mathrm{Cl}_{2} / \mathrm{H}_{2} \mathrm{O}(4: 1, \mathrm{v} / \mathrm{v})$; ii. $\mathrm{Cl}^{i} \mathrm{Pr}_{2} \mathrm{NPO}\left(\mathrm{CH}_{2}\right){ }_{2} \mathrm{CN}$, EtNiPr${ }_{2}$, THF; iii. $\mathrm{H}_{2} \mathrm{O}$, 4,5-dicyanoimidazole, $\mathrm{CH}_{3} \mathrm{CN}$; g) $\mathrm{N}$-Chlorosuccinimide, $\mathrm{EtN}^{i} \mathrm{Pr}_{2}, \mathrm{CH}_{3} \mathrm{CN}$; then DBU, $\mathrm{CH}_{3} \mathrm{CN}$; then $\mathrm{C}-18$ chromatography and cation exchange; h) $\left.\mathrm{H}_{2}, \mathrm{Pd} / \mathrm{C}, \mathrm{Et}_{3} \mathrm{~N}, t \mathrm{BuOH} / \mathrm{H}_{2} \mathrm{O} ; \mathrm{i}\right) \mathrm{78}, \mathrm{N}, \mathrm{N}-$ carbonyldiimidazole, $\mathrm{Et}_{3} \mathrm{~N}$, pyridine; then 91, $\mathrm{ZnCl}_{2}, \mathrm{DMF}$; then $\mathrm{EDTA}\left(\mathrm{Et}_{3} \mathrm{NH}^{+}\right.$form) and $\mathrm{C}-18$ chromatography; $\mathrm{j}$ ) $\mathrm{NH}_{3} / \mathrm{MeOH}(7 \mathrm{M})$; then $\mathrm{Bu}_{4} \mathrm{NF}$, THF; then precipitation, $\mathrm{C}-18$ ion pairing chromatography, and cation exchange.

Disaccharide adenosine 84 was generated from the coupling of 82 with 83 (Scheme 7B), whose orthogonal protecting groups were selectively replaced by three rounds, yielding the 5'-hydroxyl disaccharide 
adenosine 87. Phosphorylation of 5'-hydroxyl group of 87 produced compound 88 which reacted with chlorophosphate $\mathbf{8 9}$, generating the building block $\mathbf{8 0}$. Compared to solid-phase synthetic strategy described by Filippov et al., ${ }^{34}$ the liquid-phase synthetic strategy reported by Hergenrother et al. ${ }^{95}$ for forming ADPribose dimer had two obvious differences: (1) the chain elongation was designed in the opposite direction over that of the solid-phase synthetic strategy, so compound $\mathbf{8 1}$ was used as the initiator; (2) the pyrophosphate bond between ribose and disaccharide adenosine fragments was formed through the coupling of 78 with 91 which both had tetravalent phosphates, rather than the coupling between one trivalent phosphorimide and one tetravalent phosphate. Besides, the biggest advantage of Hergenrother's liqiud-phase synthetic strategy was that the final purified product $\mathbf{7 6}$ had been gained by HPLC in a high yield of $40 \%$.

Even though well-defined and homogeneous products can be obtained, length of chemically synthesized PAR is currently limited to 2 to 3 ADPR units because of a markable hindrance during solid- or liquid-phase synthetic process. It is frustrating that the more complex branched PAR which is closer to natural structure has not been obtained by chemical synthesis. On the other hand, too many reaction steps and complicated postprocessing lower yields of final products. Fortunately, this kind of short chain ADP-ribose oligomers can cover a demand for researches. ${ }^{16}$

\section{Conclusions}

This short review offers a summary of PAR from its structure to its enzymatic and chemical syntheses. PAR, a negatively charged biomacromolecule, is structurally similar to nucleic acids. Natural PAR can be synthesized by PAR polymerase families as a dendritic polymer with a size up to 400 ADPR units. PAR cannot only be covalently modified to proteins, resulting in the changes of protein-protein interactions, but also, in its free state, influence functions of proteins via non-covalent interactions. Compared to enzymatic synthesis, chemical synthesis is more likely to provide homogeneous PAR products and can reduce the difficulty of purification. However, limitations for chemical synthesis of PAR still exist because, at present, only short chain oligomers ( 2 to 3 ADPR units) can be obtained. On the other hand, branched ADP-ribose oligomers which are closer to natural structure of PAR, has not been constructed by chemical synthesis strategies. Therefore, efforts have to be paid to overcome these challenges.

\section{Acknowledgements}

This work was financially supported by National Key R\&D Program of China (2018YFA0507600, 2019YFA0904200) and National Natural Science Foundation of China (Grant/Award Numbers: 21672126).

\section{References}

1. Barnham, K. J.; Masters, C. L.; Bush, A. I. Nat. Rev. Drug Discov. 2004, 3, 205. https://dx.doi.org/10.1038/nrd1330

2. Yu, C. H.; Si, T.; Wu, W. H.; Hu, J.; Du, J. T.; Zhao, Y. F.; Li, Y. M. Biochem. Biophy. Res. Comm. 2008, $375,59$. https://dx.doi.org/10.1016/i.bbrc.2008.07.101

3. Ma, M. R.; Hu, Z. W.; Zhao, Y. F.; Chen, Y. X.; Li, Y. M. Sci. Rep. 2016, 6, 1. 
https://dx.doi.org/10.1038/srep3713

4. Gaidzik, N.; Westerlind, U.; Kunz, H. Chem. Soc. Rev. 2013, 42, 4421.

https://dx.doi.org/10.1039/c3cs35470a

5. Liu, Y. F.; Sun, Z. Y.; Chen, P. G.; Huang, Z. H.; Gao, Y.; Shi, L.; Zhao, Y. F.; Chen, Y. X.; Li, Y. M. Bioconjugate Chem. 2015, 26, 1439.

https://dx.doi.org/10.1021/acs.bioconjchem.5b00150

6. Schreiber, V.; Dantzer, F.; Ame, J. C.; de Murcia, G. Nat. Rev. Mol. Cell Biol. 2006, 7, 517. https://dx.doi.org/10.1038/nrm1963

7. Gibson, B. A.; Kraus, W. L. Nat. Rev. Mol. Cell Biol. 2012, 13, 411.

https://dx.doi.org/10.1038/nrm3376

8. Kraus, W. L. Mol. Cell 2015, 58, 902.

https://dx.doi.org/10.1016/j.molcel.2015.06.006

9. Hottiger, M. O. Mol. Cell 2015, 58, 1134.

https://dx.doi.org/10.1016/j.molcel.2015.06.001

10. Ryu, K. W.; Kraus, W. L. Mol. Cell 2016, 63, 349.

https://dx.doi.org/10.1016/j.molcel.2016.07.018

11. Wright, R. H.; Lioutas, A.; Le Dily, F.; Soronellas, D.; Pohl, A.; Bonet, J.; Nacht, A. S.; Samino, S.; Mateu, J. F.; Vicent, G. P.; Wierer, M.; Trabado, M. A.; Schelhorn, C.; Carolis, C.; Macias, M. G.; Yanes, O.; Oliva, B.; Beato, M. Science 2016, 352, 1221.

https://dx.doi.org/10.1126/science.aad9335

12. Lehmann, L. C.; Hewitt, G.; Aibara, S.; Leitner, A.; Marklund, E.; Maslen, S. L.; Maturi, V.; Chen, Y.; van der Spoel, D.; Skehel, J. M.; Moustakas, A.; Boulton, S. J.; Deindl, S. Mol. Cell 2017, 68, 847.

https://dx.doi.org/10.1016/j.molcel.2017.10.017

13. Gottschalk, A. J.; Timinszky, G.; Kong, S. E.; Jin, J.; Cai, Y.; Swanson, S. K.; Washburn, M. P.; Florens, L.; Ladurner, A. G.; Conaway, J. W.; Conaway, R. C. PNAS. 2009, 106, 13770.

https://dx.doi.org/10.1073/pnas.0906920106

14. Polo, L. M.; Xu, Y.; Hornyak, P.; Garces, F.; Zeng, Z.; Hailstone, R.; Matthews, S. J.; Caldecott, K. W.; Oliver, A. W.; Pearl, L. H. Cell Rep. 2019, 26, 573.

https://dx.doi.org/10.1016/i.celrep.2018.12.082

15. Ahel, D.; Horejsi, Z.; Wiechens, N.; Polo, S. E.; Garcia-Wilson, E.; Ahel, I.; Flynn, H.; Skehel, M.; West, S. C.; Jackson, S. P.; Owen-Hughes, T.; Boulton, S. J. Science 2009, 325, 1240.

https://dx.doi.org/10.1126/science.1177321

16. Singh, H. R.; Nardozza, A. P.; Moller, I. R.; Knobloch, G.; Kistemaker, H. A. V.; Hassler, M.; Harrer, N.; Blessing, C.; Eustermann, S.; Kotthoff, C.; Huet, S.; Mueller-Planitz, F.; Filippov, D. V.; Timinszky, G.; Rand, K. D.; Ladurner, A. G.,. Mol. Cell 2017, 68, 860.

https://dx.doi.org/10.1016/j.molcel.2017.11.019

17. Andrabi, S. A.; Kim, N. S.; Yu, S. W.; Wang, H.; Koh, D. W.; Sasaki, M.; Klaus, J. A.; Otsuka, T.; Zhang , Z. Z.; Koehler, R. C.; Hurn ,P. D.; Poirier , G. G.; Dawson, V. L. ; Hurn, P. D. PNAS 2006,103, 18308. https://dx.doi.org/10.1073/pnas.0606526103

18. Leung, A. K.; Vyas, S.; Rood, J. E.; Bhutkar, A.; Sharp, P. A.; Chang, P. Mol. Cell 2011, 42, 489. https://dx.doi.org/1016/j.molcel.2011.04.015

19. Xie, B.; Zhang, L.; Zhao, H.; Bai, Q.; Fan, Y.; Zhu, X.; Yu, Y.; Li, R.; Liang, X.; Sun, Q. Y.; Li, M.; Qiao, J. Cell Res. 2018, 28, 462.

https://dx.doi.org/10.1038/s41422-018-0009-7 
20. Bai, P. Mol. Cell 2015, 58, 947.

https://dx.doi.org/10.1016/j.molcel.2015.01.034

21. Scarpa, E. S.; Fabrizio, G.; Di Girolamo, M. FEBS J. 2013, 280, 3551.

https://dx.doi.org/10.1111/febs.12290

22. McGurk, L.; Rifai, O. M.; Bonini, N. M. Trends. Genet. 2019, 35, 601. https://dx.doi.org/10.1016/j.tig.2019.05.004

23. Kam, T. I.; Mao, X.; Park, H.; Chou, S. C.; Karuppagounder, S. S.; Umanah, G. E.; Yun, S. P.; Brahmachari, S.; Panicker, N.; Chen, R.; Andrabi, S. A.; Qi, C.; Poirier, G. G.; Pletnikova, O.; Troncoso, J. C.; Bekris, L. M.; Leverenz, J. B.; Pantelyat, A.; Ko, H. S.; Rosenthal, L. S.; Dawson, T. M.; Dawson, V. L. Science 2018, $362,1$. https://dx.doi.org/10.1126/science.aat8407

24. Hoch, N. C.; Polo, L. M. Genet. Mol. Biol. 2019, 43, 1. https://dx.doi.org/10.1590/1678-4685-GMB-2019-0075

25. Chambon, P.; Weill, J. D.; Mandel, P. Biochem. Bioph. Res. Co. 1963, 11, 39. https://dx.doi.org/10.1016/0006-291X(63)90024-X

26. Hayaishi, O.; Veda, K. Ann. Rev. Biochem. 1977, 46, 95. https://dx.doi.org/10.1146/annurev.bi.46.070177.000523

27. Alvarez-Gonzalez, R.; Jacobson, M. K.,. Biochemistry 1987, 26, 3218. https://dx.doi.org/10.1021/bi00385a042

28. Oei, S. L.; Griesenbeck, J.; Buchlow, G.; Jorcke, D.; Mayer-Kuckuk, P.; Wons, T.; Ziegler, M. FEBS Letters. 1996, 397, 17. https://dx.doi.org/10.1016/S0014-5793(96)01137-4

29. Schultheisz, H. L.; Szymczyna, B. R.; Williamson, J. R. J. Am. Chem. Soc. 2009, 131, 14571. https://dx.doi.org/10.1021/ja903155s

30. Liu, Q.; van der Marel, G. A.; Filippov, D. V. Org. Biomol. Chem. 2019, 17, 5460. https://dx.doi.org/10.1039/c9ob00501c

31. Drenichev, M. S.; Mikhailov, S. N. Bioorg. Med. Chem. Lett. 2016, 26, 3395. https://dx.doi.org/10.1016/i.bmcl.2016.06.008

32. Ryu, K. W.; Kim, D. S.; Kraus, W. L. Chem. Rev. 2015, 115, 2453. https://dx.doi.org/10.1080/15257770.2014.984073

33. Drenichev, M. S.; Mikhailov, S. N. Nucleosides, Nucleotides and Nucleic Acids 2015, 34, 258. https://dx.doi.org/10.1093/nar/4.11.3997

34. Kistemaker, H. A. V.; Lameijer, L. N.; Meeuwenoord, N. J.; Overkleeft, H. S.; van der Marel, G. A.; Filippov, D. V. Angew. Chem. Int. Ed. 2015, 54, 4915. https://dx.doi.org/10.1002/anie.201412283

35. de Murcial, G. ; Jongstra-Bilen, J.; Ittel, M. E.; Mandel, P.; Delain, E. The EMBO Joumal 1983, 2, 543. https://doi.org/10.1002/i.1460-2075.1983.tb01460.x

36. Miwa, M. ; Hazime, S. ; Sakura, H. ; Saikawa, N,; Watana, F. ; Matsushima, T. ; Sugimura, T. Nucleic Acids Research 1977, 4, 3997. https://dx.doi.org/10.1093/nar/4.11.3997

37. Ferro, A. M.; Oppenheimer, N. J. Proc. Natl. Acad. Sci. USA 1978, 75, 809. https://dx.doi.org/10.1073/pnas/75.2.809

38. Efimtseva, E. V.; Kulikova, I. V.; Mikhailov, S. N. Curr. Org. Chem. 2007, 11, 337. https://doi.org/10.2174/138527207780059367

39. Efimtseva, E. V.; Mikhailov, S. N. Russ. Chem. Rev. 2004, 73, 401. 
https://doi.org/10.1070/RC2004v073n04ABEH000847

40. Efimtseva, E. V.; Kulikova, I. V.; Mikhailov, S. N. Mol. Bio. 2009, 43, 301.

https://doi.org/10.1134/S0026893309020125

41. Davidovic, L.; Vodenicharov, M.; Affar, E. B.; Poirier, G. G. Exp. Cell Res. 2001, $268,7$. https://doi.org/10.1006/excr.2001.5263

42. Miwa, M.; Sugimura, T. J. Biol. Chem. 1971, 246, 6362.

https://pubmed.ncbi.nlm.nih.gov/4331388/

43. Desnoyers, S.; Shah, G. M. Brochu, G.; Hoflack, J. C.; Verreault, A.; Poirier, G. G. Biochimie 1995, 77,433. https://doi.org/10.1016/0300-9084(96)88156-9

44. Barkauskaite, E.; Brassington, A.; Tan, E. S.; Warwicker, J.; Dunstan, M. S.; Banos, B.; Lafite, P.; Ahel, M.; Mitchison, T. J.; Ahel, I.; Leys, D. Nat. Commun. 2013, 4, 1.

https://doi.org/10.1038/ncomms3164

45. Slade, D.; Dunstan, M. S.; Barkauskaite, E.; Weston, R.; Lafite, P.; Dixon, N.; Ahel, M.; Leys, D.; Ahel, I. Nature 2011, 477, 616.

https://doi.org/10.1038/nature10404

46. Dunstan, M. S.; Barkauskaite, E.; Lafite, P.; Knezevic, C. E.; Brassington, A.; Ahel, M.; Hergenrother, P. J.; Leys, D.; Ahel, I. Nat. Commun. 2012, 3, 878.

https://doi.org/10.1038/ncomms1889

47. Zaja, R.; Mikoc, A.; Barkauskaite, E.; Ahel, I. Biomolecules 2012, 3, 1.

https://doi.org/10.3390/biom3010001

48. Liu, C.; Vyas, A.; Kassab, M. A.; Singh, A. K.; Yu, X. Nucleic Acids Res. 2017, 45, 8129.

https://dx.doi.org/10.1093/nar/gkx565

49. Qi, H.; Price, B. D.; Day, T. A. Trends Genet. 2019, 35, 159.

https://dx.doi.org/10.1016/j.tig.2018.12.002

50. O'Sullivan, J.; Tedim Ferreira, M.; Gagne, J. P.; Sharma, A. K.; Hendzel, M. J.; Masson, J. Y.; Poirier, G. G. Nat. Commun. 2019, 10, 1182.

https://doi.org/10.1038/s41467-019-08859-x

51. Panzeter, P. L.; Realini, C. A.; Althaus, F. R. Biochemistry 1992, 31, 1379.

https://doi.org/10.1021/bi00120a014

52. Nozaki, T.; Masutani, M.; Akagawa, T.; Sugimura, T.; Esumi, H. Biochem. Biophys. Res. Commun. 1994, 198,45 .

https://doi.org/10.1006/bbrc.1994.1007

53. Malanga, M.; Farina, B. Biol. Chem. 2000, 381, 1047.

https://doi.org/10.1515/BC.2000.129

54. Altmeyer, M.; Neelsen, K. J.; Teloni, F.; Pozdnyakova, I.; Pellegrino, S.; Grofte, M.; Rask, M. D.; Streicher, W.; Jungmichel, S.; Nielsen, M. L.; Lukas, J. Nat. Commun. 2015, 6, 8088.

https://doi.org/10.1038/ncomms9088

55. Reale, A.; Matteis, G. D.; Galleazzi, G.; Zampieri, M.; Caiafa, P. Oncogene 2005, 24, 13. https://doi.org/10.1038/sj.onc.1208005

56. Fahrer, J.; Popp, O.; Malanga, M.; Beneke, S.; Markovitz, D. M.; Ferrando-May, E.; Burkle, A.; Kappes, F. Biochemistry 2010, 49, 7119. https://doi.org/10.1021/bi004365

57. Popp, O.; Veith, S.; Fahrer, J.; Bohr, V. A.; Burkle, A.; Mangerich, A. ACS Chem. Biol. 2013, 8, 179. https://doi.org/10.1021/cb300363 
58. Kalisch, T.; Ame, J. C.; Dantzer, F.; Schreiber, V. Trends Biochem. Sci. 2012, 37, 381.

https://dx.doi.org/10.1016/j.tibs.2012.06.001

59. Teloni, F.; Altmeyer, M. Nucleic Acids Res. 2016, 44, 993.

https://dx.doi.org/10.1093/nar/gkv1383

60. Lin, S. J.; Guarente, L. Curr. Opin. Cell Biol. 2003, 15, 241-246.

https://dx.doi.org/10.1016/S0955-0674(03)00006-1

61. Alemasova, E. E.; Lavrik, O. I. Nucleic Acids Res. 2019, 47, 3811.

https://dx.doi.org/10.1093/nar/gkz120

62. Chen, Q.; Kassab, M. A.; Dantzer, F.; Yu, X. Nat. Commun. 2018, 9, 3233.

https://doi.org/10.1038/s41467-018-05588-5

63. Jiang, H. ; Kim, J. H.; Frizzell, K. M. ; Kraus, W. L.; Lin, H. J. Am. Chem. Soc. 2010, 132, 9363.

https://doi.org/10.1021/ja101588r

64. Wang, Y.; Rosner, D.; Grzywa, M.; Marx, A. Angew. Chem. Int. Ed. 2014, 53, 8159.

https://dx.doi.org/10.1002/anie.201404431

65. Carter-O'Connell, I.; Jin, H.; Morgan, R. K.; David, L. L.; Cohen, M. S. J. Am. Chem. Soc. 2014, 136, 5201. https://doi.org/10.1021/ja412897a

66. Nottbohm, A. C.; Dothager, R. S.; Putt, K. S.; Hoyt, M. T.; Hergenrother, P. J. Angew. Chem. Int. Ed. 2007, 46, 2066.

https://dx.doi.org/10.1002/anie.200603988

67. Wallrodt, S.; Buntz, A.; Wang, Y.; Zumbusch, A.; Marx, A. Angew. Chem. Int. Ed. 2016, 55, 7660.

https://dx.doi.org/10.1002/anie.201600464

68. Efimtseva, E. V.; Mikhailov, S. N. Biochemistry 2002, 67, 1136.

https://doi.org/10.1023/A:1020963207320

69. Flynn, E. H.; Hinman, J. W.; Caron, E. L.; Woolf, D. O. J. Am. Chem. Soc. 1953, 75, 5867.

https://doi.org/10.1021/ja01119a025

70. Kim, S. H.; Yoo, S. M.; Park,S.; Kim, Y. H. J. Nat. Prod. 2000, 63, 1188.

https://doi.org/10.1021/np0000724

71. Sylla, B.; Gauthier, C.; Legault, J.; Fleury, P. Y.; Lavoie, S.; Mshvildadze, V.; Muzashvili, T.; Kemertelidze, E.; Pichette, A. Carbohydr. Res. 2014, 398, 80.

https://dx.doi.org/10.1016/j.carres.2014.06.027

72. Mikhailov, S. N.; Efimtseva, E. V.; Rodionov, A. A.; Shelkunova, A. A.; Rozenski,J.; Emmerechts, G.; Schepers, G.; Aerschot, A. V.; Herdewijn, P. Chem. Biodivers. 2005, 2, 1153.

https://dx.doi.org/10.1002/cbdv.200590085

73. Mikhailov, S. N.; Kulikova, I. V.; Nauwelaerts, K.; Herdewijn, P. Tetrahedron 2008, 64, 2871.

https://dx.doi.org/10.1016/j.tet.2008.01.028

74. Mikhailov, S. N.; Drenichev, M. S.; Oslovsky, V. E.; Kulikova, I. V.; Herdewijn, P. Curr. Protoc. Nucleic Acid Chem. 2019, 78, 1.

https://dx.doi.org/10.1002/cpnc.92

75. Kulikova, I. V.; Muradova, D. A.; Drenichev, M. S.; Mikhailov, S. N. Chem. Nat. Comp. 2015, 51, 256. https://dx.doi.org/10.1007/s10500-015-1256-1

76. van der Heden van Noort, G. J.; Overkleeft, H. S.; van der Marel, G. A.; Filippov, D. V. Org. Lett. 2011, 13, 2921.

https://doi.org/10.1021/ol200971z

77. Zheng, M.; Mex, M.; Gotz, K. H.; Marx, A. Org. Biomol. Chem. 2018, 16, 8904. 
https://doi.org/10.1039/c8ob01894d

78. Someya, H.; Itoh, T.; Aoki, S. Molecules 2017, 22, 1.

https://doi.org/10.3390/molecules22101650

79. Someya, H.; Itoh, T.; Kato, M.; Aoki, S. J. Vis. Exp. 2018, 137, 1.

https://doi.org/10.3791/57897

80. Liu, Q.; Kistemaker, A. A. V.; Overkleeft, H.S.; van der Marel, G. A.; Filippov, D. V. Chem. Commun. 2017, 53, 10255.

https://doi.org/10.1039/C7CC05755E

81. Kistemaker, H. A. V.; Overkleeft, H. S.; van der Marel, G. A.; Filippov, D. V. Org. Lett. 2015, $17,4328$. https://doi.org/10.1021/acs.orglett.5b02143

82. Van Rompay, A. R.; Johansson, M.; Karlsson, A. Pharmacol. Ther. 2000, 87, 189. https://dx.doi.org/10.1016/s0163-7258(00)0004

83. Geeson, M. B.; Cummins, C. C. ACS Cent. Sci. 2020. https://doi.org/10.1021/acscentsci.0c00332

84. Spicer, C. D.; Pujari-Palmer, M.; Autefage, H.; Insley, G.; Procter, P.; Engqvist, H.; Stevens, M. M. ACS Cent.Sci. 2020, 6, 226. https://doi.org/10.1021/acscentsci.9b01149

85. Domon, K.; Puripat, M.; Fujiyoshi, K.; Hatanaka, M.; Kawashima, S. A.; Yamatsugu, K.; Kanai, M. ACS Cent. Sci. 2020, 6, 283.

https://doi.org/10.1021/acscentsci.9b01272

86. Malwal, S. R.; O'Dowd, B.; Feng, X.; Turhanen, P.; Shin, C.; Yao, J.; Kim, B. K.; Baig, N.; Zhou, T.; Bansal, S.; Khade, R. L.; Zhang, Y.; Oldfield, E. J. Am. Chem. Soc. 2018, 140, 7568.

https://doi.org/10.1021/jacs.8b02363

87. Shepard, S. M.; Windsor, I. W.; Raines, R. T.; Cummins, C. C. J. Am. Chem. Soc. 2019, 141, 18400. https://doi.org/10.1021/jacs.9b09760

88. Ahmadibeni, Y.; Parang, K. Org. Lett. 2005, 7, 5589. https://doi.org/10.1021/ol0521432

89. Xu, Z. Bioorg. Med. Chem. Lett. 2015, 25, 3777. http://dx.doi.org/10.1016/j.bmcl.2015.06.094

90. Ahmadibeni, Y.; Parang, K. Org. Lett. 2007, 9, 4483. https://doi.org/10.1021/ol7018778

91. Ahmadibeni, Y.; Parang, K. Angew. Chem. Int. Ed. 2007, 46, 4739. https://dx.doi.org/10.1002/anie.200605029

92. van der Heden van Noort, G. J.; van der Horst, M. G.; Overkleeft, H. S.; van der Marel, G. A.; Filippov, D. V. J. Am. Chem. Soc. 2010, 132, 5236.

https://doi.org/10.1021/ja910940q

93. van der Heden van Noort, G. J. ACS Omega 2020, 5, 1743. https://doi.org/10.1021/acsomega.9b03591

94. Kistemaker, H. A. V.; van der Heden van Noort, G. J.; Overkleeft, H. S.; van der Marel, G. A.; Filippov, D. V. Org. Lett. 2013, 15, 2306.

https://doi.org/10.1021/ol400929c

95. Lambrecht, M. J.; Brichacek, M.; Barkauskaite, E.; Ariza, A.; Ahel, I.; Hergenrother, P. J. J. Am. Chem. Soc. 2015, 137, 3558. https://doi.org/10.1021/ja512528p 


\section{Authors' Biographies}

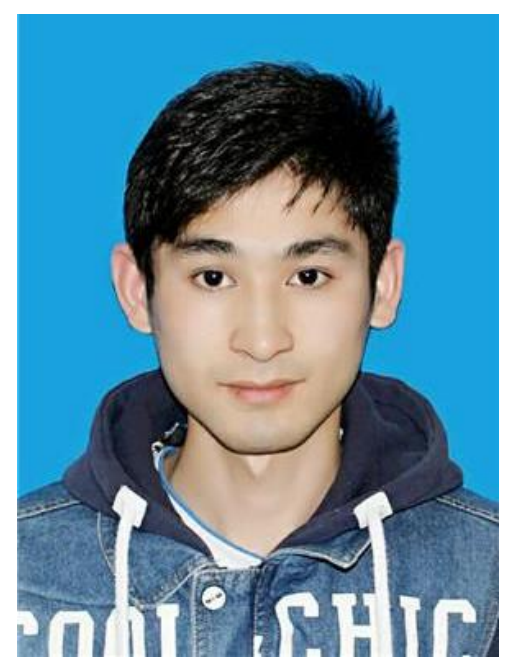

Lang Zhao graduated from the School of Chemistry and Chemical Engineering, Hubei University with a Bachelor Degree in 2018. September of the same year, he was admitted to the Department of Chemistry, Tsinghua University as a PhD student, under the guidance of Prof. Yan-Mei Li. He is currently focused on the designing of antitumor vaccines and innate immune system agonists.

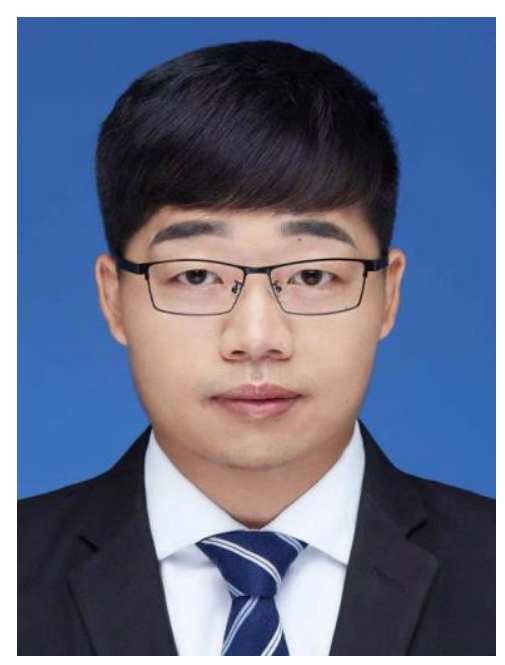

Jun J. Wu graduated from the School of Chemistry and Chemical Engineering, Hubei University with a BSc degree in 2015. Since 2015, he has been studying for a chemistry PhD at the Department of Chemistry, Tsinghua University under the guidance of Prof. Yan M. Li. His research focuses on the synthesis and application of STING agonists in immunotherapy. 


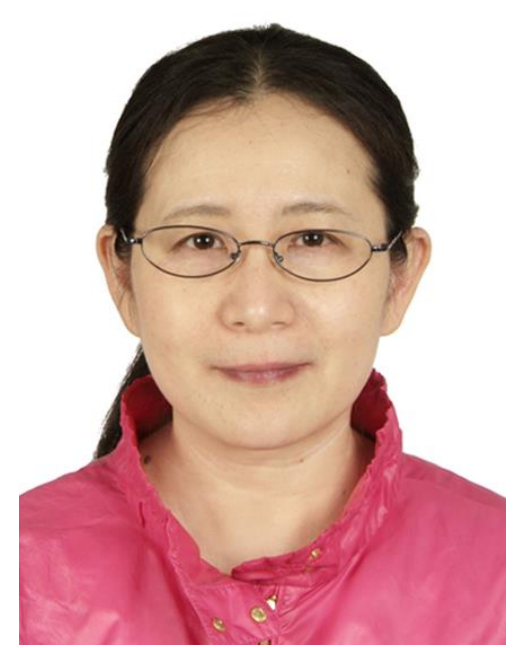

Yan M. Li received her BSc and M.S. in the Department of Chemistry, Tsinghua University of China in 1987 and 1989, respectively. She obtained her Ph.D. in the same department of Tsinghua University under the guidance of Prof. Yu F. Zhao in 1992. Between 1996 and 1997, she did the postdoctoral training in Karlsruhe University with Prof. Herbert Waldmann. She is now a professor in the Department of Chemistry, Tsinghua University. Currently, her research interests are focused on the chemical synthesis of vaccines and immunostimulants such as STING agonists and their application in immunotherapy. 